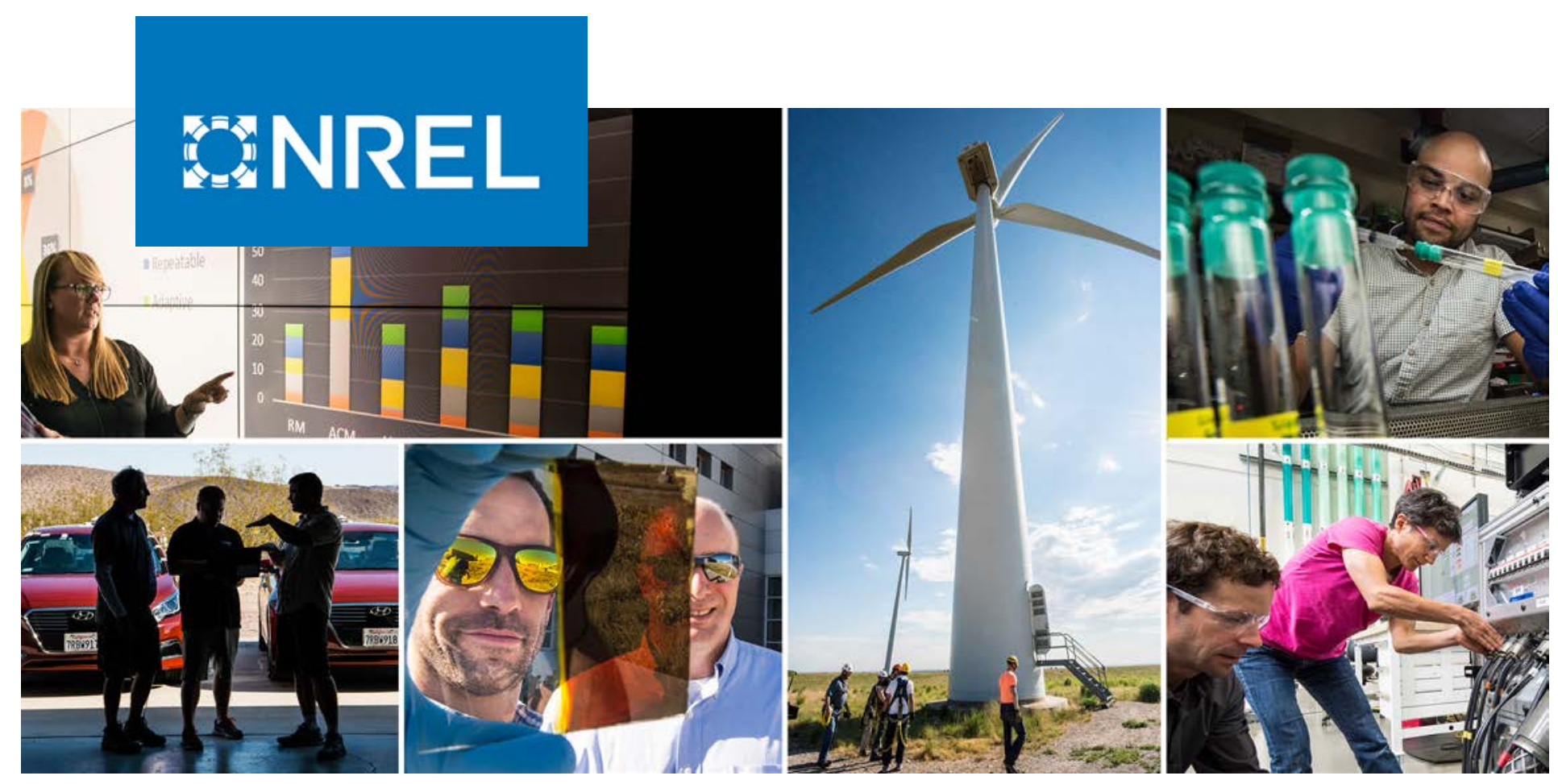

\title{
Jamaica Transportation Greenhouse Gas Reduction Plan
}

Caley Johnson, Sam Koebrich, and Mark Singer

National Renewable Energy Laboratory

NREL is a national laboratory of the U.S. Department of Energy

Office of Energy Efficiency \& Renewable Energy

Operated by the Alliance for Sustainable Energy, LLC

This report is available at no cost from the National Renewable Energy Laboratory (NREL) at www.nrel.gov/publications.

\section{Technical Report}

NREL/TP-5400-73380

April 2019 


\title{
GHREL
}

\section{Jamaica Transportation Greenhouse Gas Reduction Plan}

\author{
Caley Johnson, Sam Koebrich, and Mark Singer
}

National Renewable Energy Laboratory

\section{Suggested Citation}

Johnson, Caley, Sam Koebrich, and Mark Singer. 2019. Jamaica Transportation Greenhouse Gas Reduction Plan. Golden, CO: National Renewable Energy Laboratory.

NREL/TP-5400-73380. https://www.nrel.gov/docs/fy19osti/73380.pdf.

NREL is a national laboratory of the U.S. Department of Energy Office of Energy Efficiency \& Renewable Energy Operated by the Alliance for Sustainable Energy, LLC

This report is available at no cost from the National Renewable Energy Laboratory (NREL) at www.nrel.gov/publications.

Contract No. DE-AC36-08GO28308
Technical Report

NREL/TP-5400-73380

April 2019

National Renewable Energy Laboratory 15013 Denver West Parkway Golden, CO 80401

303-275-3000 • www.nrel.gov 


\section{NOTICE}

This work was authored by the National Renewable Energy Laboratory, operated by Alliance for Sustainable Energy, LLC, for the U.S. Department of Energy (DOE) under Contract No. DE-AC36-08G028308. Funding provided by the U.S. Department of State. The views expressed herein do not necessarily represent the views of the DOE or the U.S. Government.

This report is available at no cost from the National Renewable Energy Laboratory (NREL) at www.nrel.gov/publications.

U.S. Department of Energy (DOE) reports produced after 1991 and a growing number of pre-1991 documents are available free via www.OSTI.gov.

Cover Photos by Dennis Schroeder: (clockwise, left to right) NREL 51934, NREL 45897, NREL 42160, NREL 45891, NREL 48097, NREL 46526.

NREL prints on paper that contains recycled content. 


\section{Acknowledgments}

The authors would like to thank Gerald Lindo of the United States Agency for International Development for his guidance throughout this project. They would also like to thank the following people for sharing their insight and offering guidance and valuable data: Raymond Bynes (All Island United Route Taxi Association); Ludlow Powell (Island Traffic Authority); André Williams (Jamaica Customs Agency); Selena Mohammed-Wilson and Carla Barrett (Jamaican Urban Transit Company); Shauna Trowers (Ministry of Finance); Betsy Bandy, Horace Buckley, and Dwight Lewis (Ministry of Science Energy and Technology); Paula Brown (Ministry of Transport and Mining); Aisha Jones (National Commission on Science and Technology); Michael Saunderson (National Works Agency); and Heather Pinnock (Urban Development Corporation). This report has benefitted greatly from these people's help, but any mistakes are entirely the authors' responsibility. 


\section{List of Acronyms}

B5

$5 \%$ biodiesel / 95\% diesel

B20

$20 \%$ biodiesel $/ 80 \%$ diesel

BAU business as usual

BNEF Bloomberg New Energy Finance

$\mathrm{CO}_{2} \mathrm{e} \quad$ carbon dioxide equivalent

E10 $\quad 10 \%$ ethanol $/ 90 \%$ gasoline

e-bus electric bus

EV electric vehicle

GDP gross domestic product

GHG greenhouse gas

GOJ Government of Jamaica

HDV heavy-duty vehicle

HEV hybrid electric vehicle

INDC Intended Nationally Determined Contribution

IR idle reduction

kg kilogram

$\mathrm{km} \quad$ kilometer

L liter

LDV light-duty vehicle

MDV medium-duty vehicles

SUV Sport Utility Vehicle

TMT thousand metric tons

UCO used cooking oil

VKT vehicle kilometers traveled 


\section{Table of Contents}

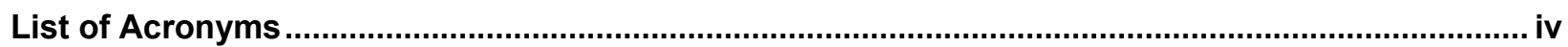

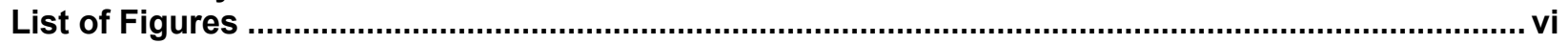

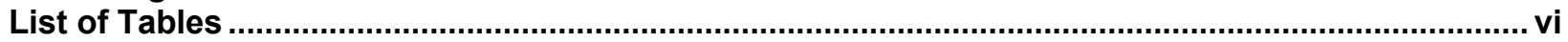

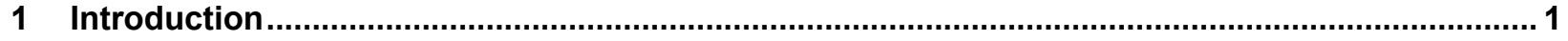

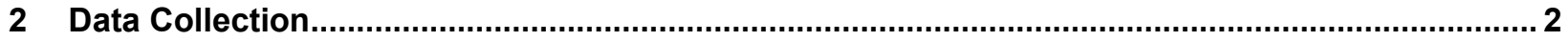

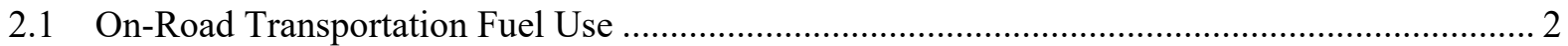

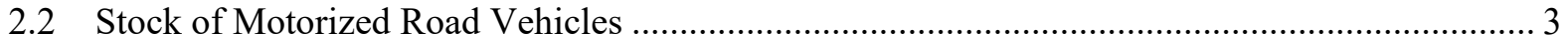

2.3 Per-Capita Vehicle Kilometers Travelled ............................................................................. 5

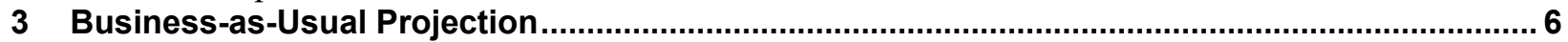

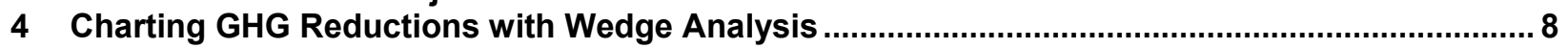

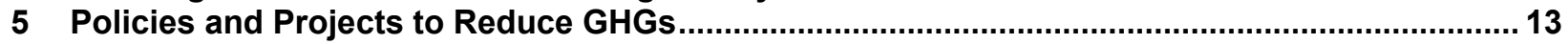

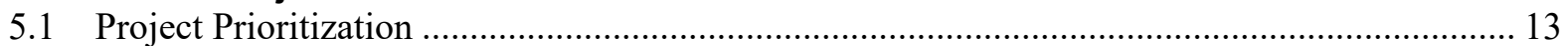

5.2 Set Vehicle Taxes and Import Duty based on GHG Emissions ............................................. 13

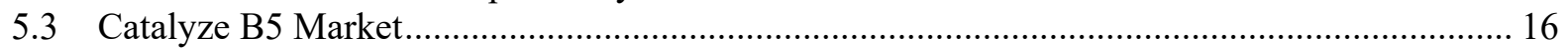

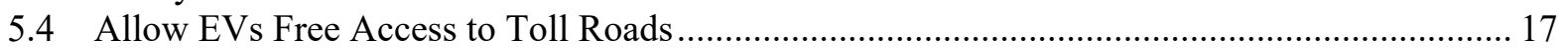

5.5 Limit HDV Idle Time with the Help of IR Technologies ......................................................... 17

5.6 Develop a Parking Management Program for Kingston that Focuses on Reducing VKT .......... 19

5.7 Coordinate Route Taxis to Enable Higher-Capacity Vehicles ................................................. 20

5.8 Track Buses and Show Live Transit Updates in Google Maps ................................................ 21

5.9 Provide Pedestrians and Cyclists with Safety Reflectors and Lights .................................... 23

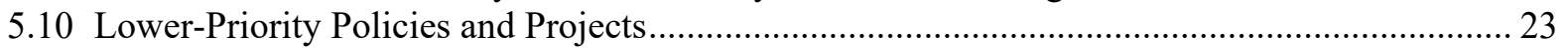

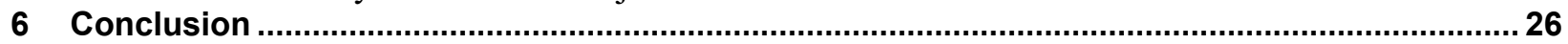

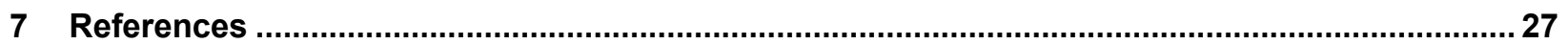

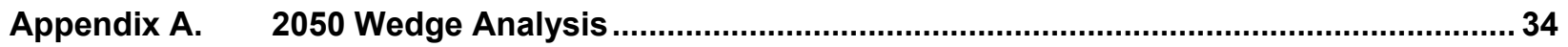

Appendix B. Supplemental Wedge Model Details ..................................................................... 38

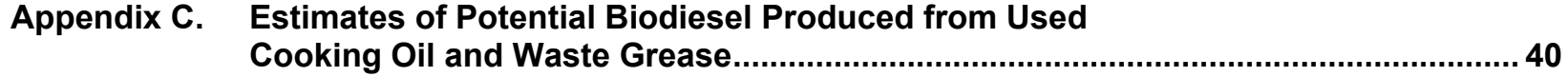




\section{List of Figures}

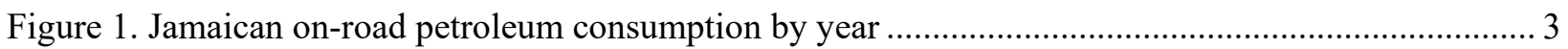

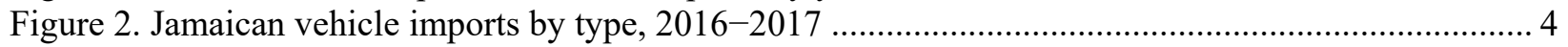

Figure 3. VKT of motorized passenger travel and per-capita GDP for 22 developed countries ................. 6

Figure 4. Jamaica on-road GHG emissions, BAU scenario .............................................................. 7

Figure 5. Reduction wedges to meet Jamaica's 10\% below BAU by 2030 goal ..................................... 9

Figure 6. Number of Jamaicans by usual mode of transportation in Jamaica.......................................... 10

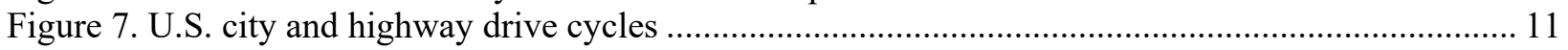

Figure 8. GHG emissions benefits of electric vehicles in Jamaica ...................................................... 12

Figure 9. Sign marking "no idling zone" with number to report infractions ......................................... 18

Figure 10. Smart phone screen shot displaying live transit updates on Google Maps............................. 22

Figure A1. Reduction wedges to reduce Jamaica's transport emissions $80 \%$ below BAU by 2050 .......... 34

\section{List of Tables}

Table 1. 2016-2017 Jamaican On-Road Vehicle Imports by Fuel Type ................................................. 4

Table 2. Key Inputs and Outputs of the Iterative Model Determining VKT per Capita............................ 5

Table 3. Subgoals, Their Predicted GHG Reduction, and Percent Contribution to Overall Goals............... 8

Table 4. Policies and Projects to Reduce GHG Emissions from Ground Transportation in Jamaica......... 15

Table 5. Fuel Economy Examples for High-Capacity Route Taxis in L/100 passenger-km .................... 21

Table A1. Subgoals, Their Predicted GHG Reduction, and Percent Contribution to Overall 2050 Goals. 35 


\section{Introduction}

The Nationally Determined Contribution Leadership Compact aims to strengthen countries' nationally determined contributions through the technical assessment of policy options to enable them to reduce their greenhouse gas (GHG) emissions. In particular, the objective of this assessment of transportation options is to assist the Government of Jamaican (GOJ) as it develops a revised, resilient National Transport Policy. This policy, among other activities, will address transportation's role in meeting Jamaica's GHG reduction goals.

This report aims to inform the revised National Transport Policy so that it aligns with Jamaica's overall GHG reduction targets and enables the road transportation sector to contribute toward these targets. First, this report highlights metrics that are key to understanding a national transportation system and its potential for GHG reductions. Second, this report develops a business-as-usual (BAU) scenario for where Jamaica's GHG emissions are headed into 2030. Third, it analyzes ways for the land transportation sector to meet Jamaica's goal of $10 \%$ below BAU by 2030 (United Nations 2015). Finally, it assesses projects that can achieve Jamaica's GHG reduction goal and ranks them by cost, size of GHG reduction, timeframe, and ancillary benefits.

This report focuses on road transportation for two main reasons. First, the Jamaican government claims full responsibility for road emissions in accordance with international GHG accounting standards whereas most air and marine emissions are international and therefore are shared among multiple countries. Second, there are many more feasible options for reducing emissions from road transportation than for air or marine transportation. 


\section{Data Collection}

Three of the most important pieces of information when reducing GHG emissions from a country's transport system are the quantity of fuel used, the vehicles that used that fuel, and the kilometers $(\mathrm{km})$ that those vehicles travelled. These three pillars can be used to derive secondary information that helps determine the best way to limit GHG emissions. This section describes these values for Jamaica, where they were obtained, the processes by which proxy data were developed for items that Jamaica does not track, and recommendations for how to track and store data in the future.

\subsection{On-Road Transportation Fuel Use}

The Ministry of Science, Energy and Technology keeps good records of gasoline and diesel consumption and posts them on its website (Ministry of Science, Energy and Transportation 2018). The data cover 2004 to 2016 and are broken down both by product and activity. We brought the two datasets into agreement by assuming that all gasoline and gasoline with $10 \%$ ethanol (E10) went to road transportation and that the product "auto diesel" was used in both road and off-road transportation. The portion of the "auto diesel" (in the product-oriented list) devoted to road transport was the difference between the quantity listed as "petroleum consumption by road and rail transportation" (in the activity-oriented list) and the quantity of gasoline (in the product-oriented list). This passed data checks, including a gasoline/diesel ratio similar to that seen in other countries. One flaw found in the product-oriented data is that we believe it double counts the gasoline and E10 during the three-year transition from the former dataset to the latter one (2008-2010). We believe this because the total gasoline used for 2009-2010 were major outliers. Therefore, this error was corrected in our dataset (Figure 1) by eliminating the double counting. 


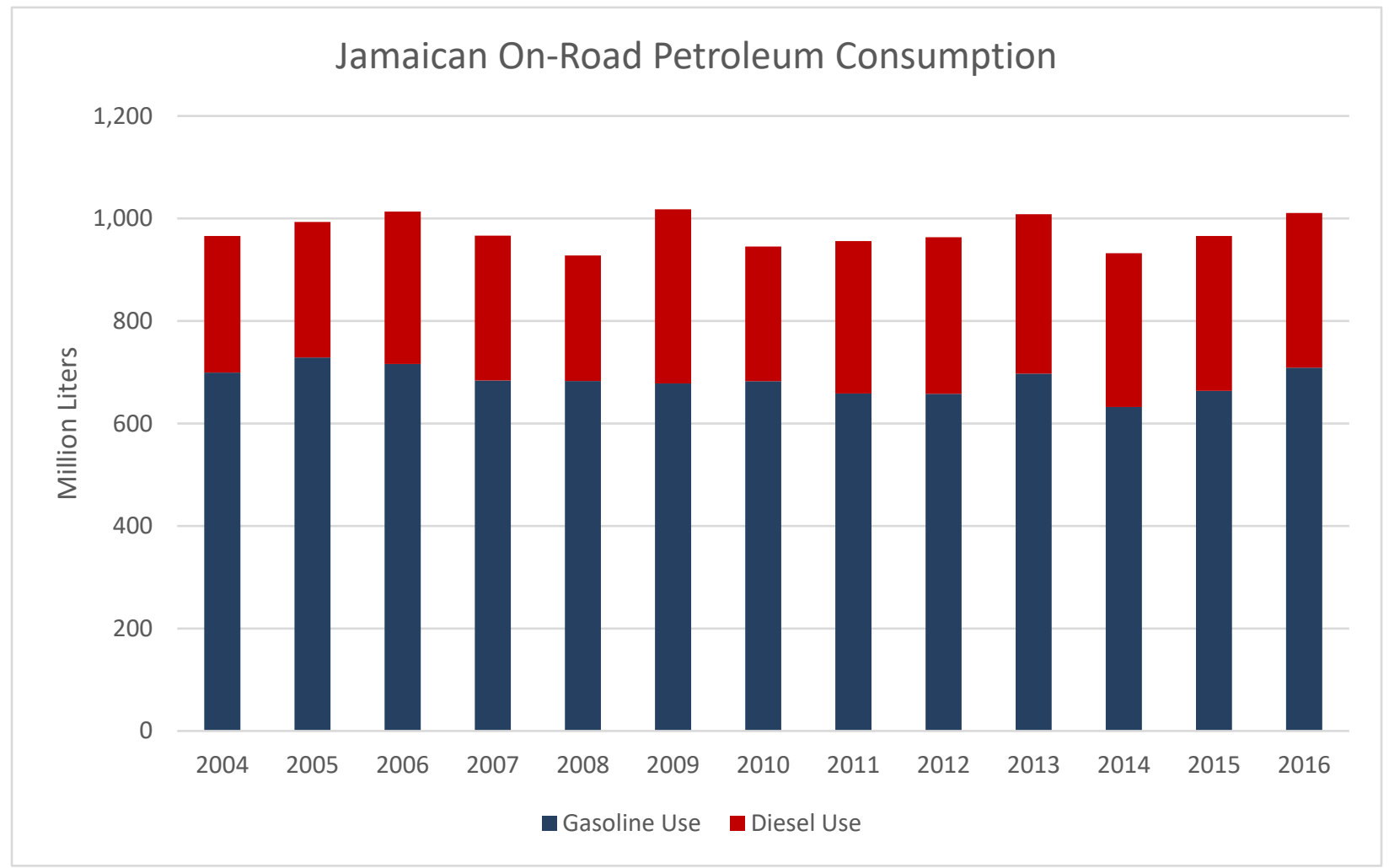

Figure 1. Jamaican on-road petroleum consumption by year

\subsection{Stock of Motorized Road Vehicles}

Jamaica does not have an electronic database of currently registered vehicles. The Tax Administration of Jamaica has a record of all vehicles that were imported but keeps no record of vehicle retirements, and hence there is no record of current vehicle rolling stock. The Island Traffic Authority issues vehicle fitness certificates, but these are currently done only in hardcopy and are consequently inaccessible.

Therefore, we derived a list of vehicle rolling stock and began our stock analysis by identifying automotive imports by vehicle type in the following way. First, customs data were used to create a database of vehicle imports for 2016-2017 to serve as a snapshot of recent vehicle purchases in Jamaica. Vehicles in this database were then categorized according to definitions laid out by the U.S. Federal Highway Administration (Alternative Fuels Data Center 2014) and the U.S. Department of Energy's fuel economy database (U.S. Department of Energy 2019). Figure 2 shows the relative quantities of imports for each vehicle category, and Table 1 displays the percent of light-duty vehicles (LDVs), medium-duty vehicles (MDVs), and heavy-duty vehicles (HDVs) by fuel type. Some 1,309 hybrid electric vehicles (HEVs) in the import data were allocated to their respective fuel type (gasoline or diesel). The most prevalent fuels in the "other" category were liquid petroleum gas (65 vehicles) and all-electric vehicles (44). From the import data, we were also able to determine that the average vehicle age when imported to Jamaica was 3.6 years. 
Table 1. 2016-2017 Jamaican On-Road Vehicle Imports by Fuel Type

\begin{tabular}{llll}
\hline & Gasoline & Diesel & Other \\
\hline LDV & $91 \%$ & $9 \%$ & $0.2 \%$ \\
MDV/HDV & $9 \%$ & $90 \%$ & $0.8 \%$ \\
All Vehicles & $88 \%$ & $12 \%$ & $0.2 \%$ \\
\hline
\end{tabular}

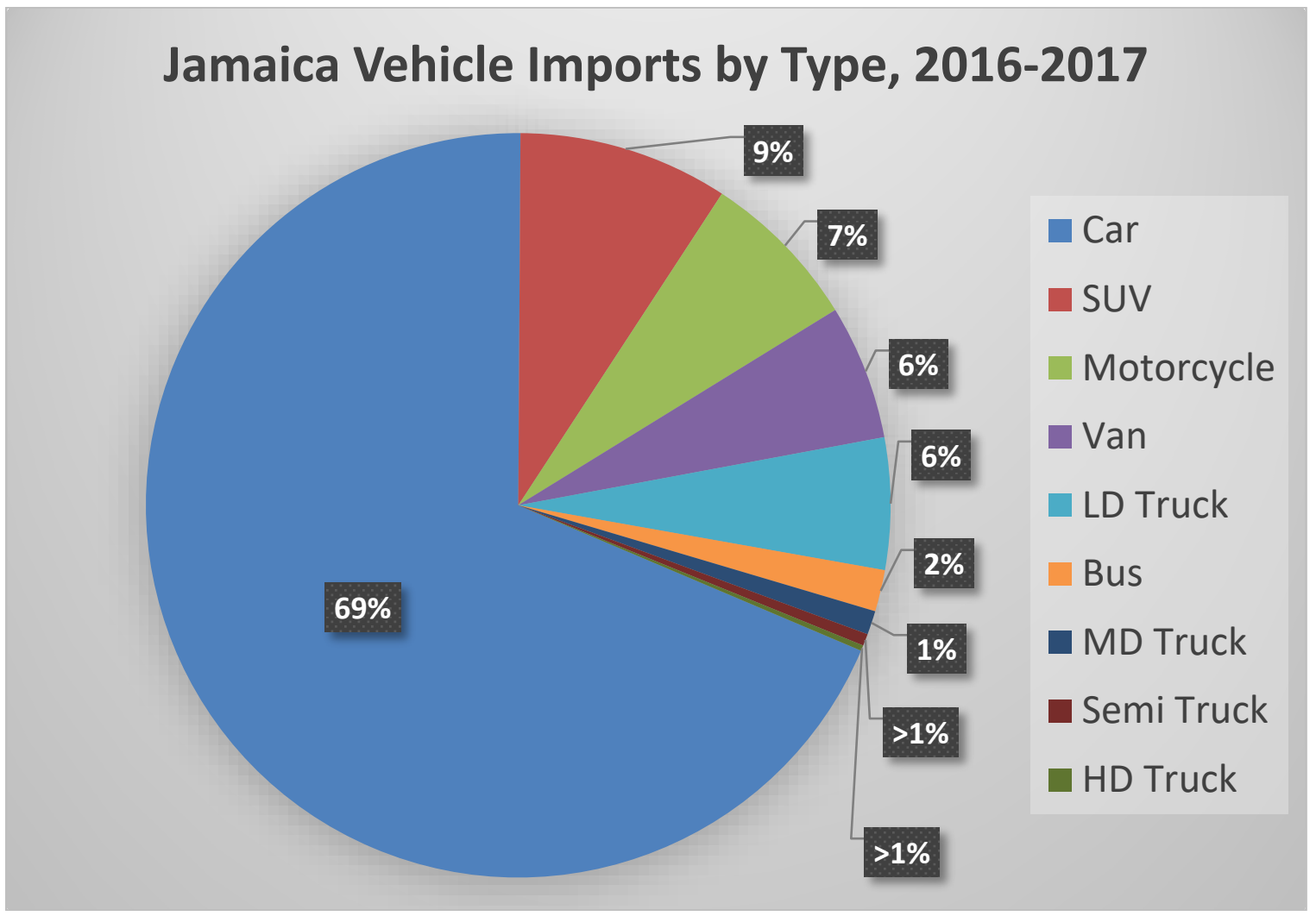

Figure 2. Jamaican vehicle imports by type, 2016-2017

To derive the approximate total vehicle stock, we began with data tracked by the World Bank (World Bank 2013) describing the number of vehicles per thousand people (tracked for 2005-2010, except for 2007). There was no significant annual growth trend in the data. Therefore, we took the median across all available years, resulting in 187.5 vehicles (including buses and freight) per 1,000 people. This is in agreement with 2011 Census data that show $18.5 \%$ of those 15 years of age and older travel primarily by private vehicle (Statistical Institute of Jamaica 2011). This $18.8 \%$ figure is multiplied by the 2016 population of Jamaica, equating to a vehicle stock of 540,325 without motorcycles (since the World Bank did not count motorcycles in its statistic), or 580,994 when the motorcycle population is added in (assuming motorcycles are $7 \%$ of stock since they are $7 \%$ of imports).

To check this derived vehicle stock number, we need to compare the vehicle stock with annual imports to ensure that it results in a realistic vehicle age of retirement. Dividing 580,994 vehicles by a purchase rate of 52,046 vehicles per year indicates that vehicles are kept for 11.2 years. The Jamaican import data indicate that the average vehicle gets imported when it is 3.6 years old. 
This means that vehicles are being retired an average of 14.8 years after the original purchase. This is quite close to the average retirement age of 16.9 years seen in the United States (Davis et al. 2013), which validates the approximate figure calculated for Jamaica.

\subsection{Per-Capita Vehicle Kilometers Travelled}

Vehicle kilometers travelled (VKT) is not tracked in Jamaica so it needs to be extrapolated from Jamaica's fuel consumption and data from similar countries. This was done through an iterative process using Microsoft Excel's Goal Seek, as shown in Table 2 and described below:

1. Total VKT was first estimated based on total fuel consumption and estimated fuel efficiency. The gasoline and diesel consumption (as reported in Section 2.1) are reproduced in the "Combined" row for the "Gasoline Consumed," "Diesel Consumed," and "Total Petroleum Consumed" columns in Table 2. These fuel volumes were allocated to LDVs and HDVs (filling in the two rows above the Combined total) based on the ratio of vehicle imports. The fuel economy of LDVs was taken as the 2008 average for vehicle purchases in non-Organization for Economic Co-operation and Development countries (International Energy Agency 2017), and fuel economy for MDVs and HDVs was based on the most numerous vehicles in the vehicle import data. The VKT of the MDV/HDV vehicle category was originally set as $23 \%$ of total VKT, based on the ratio seen in New Zealand (New Zealand Ministry of Transport 2018), one of the few other insular mountainous countries with such data available.

2. With the model thus set, Goal Seek was then used iteratively to bring VKT and petroleum consumption numbers into agreement. First, the VKT per capita was calculated so that the total petroleum consumed would equal the known 1,011 million L. When the total petroleum balanced but the diesel and gasoline amounts were off, Goal Seek minimized these deviations by adjusting the ratio between the VKT seen in LDVs and the VKT seen in MDVs/HDVs. The optimal ratio was $14 \%$ of all VKT being MDV/HDVs, which is acceptable because it is in between the metric reported for the United States (10\%) (U.S. Department of Transportation 2018) and New Zealand (23\%). The first step was then repeated, which brought the LDV VKT per capita to 2,887 in order to match total petroleum consumption of 1,011 million L. This VKT estimate fits well with other countries with a similar per-capita gross domestic product (GDP), as described by Ecola et al. (2014) and elaborated in the next section. Finally, Goal Seek was used to decrease the fuel economy of LDVs slightly to $9 \mathrm{~L} / 100 \mathrm{~km}$ so that the quantity of gasoline consumed balanced the amount the vehicles demanded.

Table 2. Key Inputs and Outputs of the Iterative Model Determining VKT per Capita

\begin{tabular}{lllllll}
\hline $\begin{array}{l}\text { Vehicle } \\
\text { Category }\end{array}$ & $\begin{array}{l}\text { VKT } \\
\text { per } \\
\text { capita }\end{array}$ & $\begin{array}{l}\text { Population } \\
\mathbf{( 2 0 1 6 )}\end{array}$ & $\begin{array}{l}\text { Fuel } \\
\text { Economy } \\
\text { (L/100 km) }\end{array}$ & $\begin{array}{l}\text { Gasoline } \\
\text { Consumed } \\
\text { (million L) }\end{array}$ & $\begin{array}{l}\text { Diesel } \\
\text { Consumed } \\
\text { (million L) }\end{array}$ & $\begin{array}{l}\text { Total } \\
\text { Petroleum } \\
\text { Consumed } \\
\text { (million L) }\end{array}$ \\
\hline LDV & 2,887 & $2,881,355$ & 9.0 & 685 & 66 & 750 \\
MDV/HDV & 471 & $2,881,355$ & 19.2 & 24 & 236 & 260 \\
Combined & 3,357 & $2,881,355$ & 10.4 & 709 & 302 & 1,011 \\
\hline
\end{tabular}




\section{Business-as-Usual Projection}

To incorporate transportation GHG emissions in Jamaica's 2030 GHG reduction goal, a BAU scenario needs to be created. To do so, we assume that fuel economy remains constant, and therefore, fuel use is driven by increases in VKT. Historically, the period of greatest growth in VKT, and consequently land transportation fuel use, is when a country's per-capita GDP (in 1990 International Dollars ${ }^{1}$ ) is between $\$ 5,000$ and $\$ 20,000$ USD (Ecola et al. 2014). In other words, this is the range where VKT growth is on the steep part of the S-curve (see Figure 3). Jamaica's per-capita GDP is currently in the low end of this range. Therefore, it is better to base projections on what other countries have done throughout this phase rather than Jamaica's previous transportation fuel consumption.

Ecola et al. (2014) found that personal VKT is most closely tied to per-capita GDP in international dollars. This relationship is shown in Figure 3, with the differences between countries being largely due to spatial dispersion of the population, car infrastructure, fuel prices, and availability of alternatives to driving. Please note that Figure 3 reflects personal VKT and omits freight and deliveries. Furthermore, Figure 3 is presented in 1990 International Dollars to be compatible with the Ecola et al. (2014) analysis.

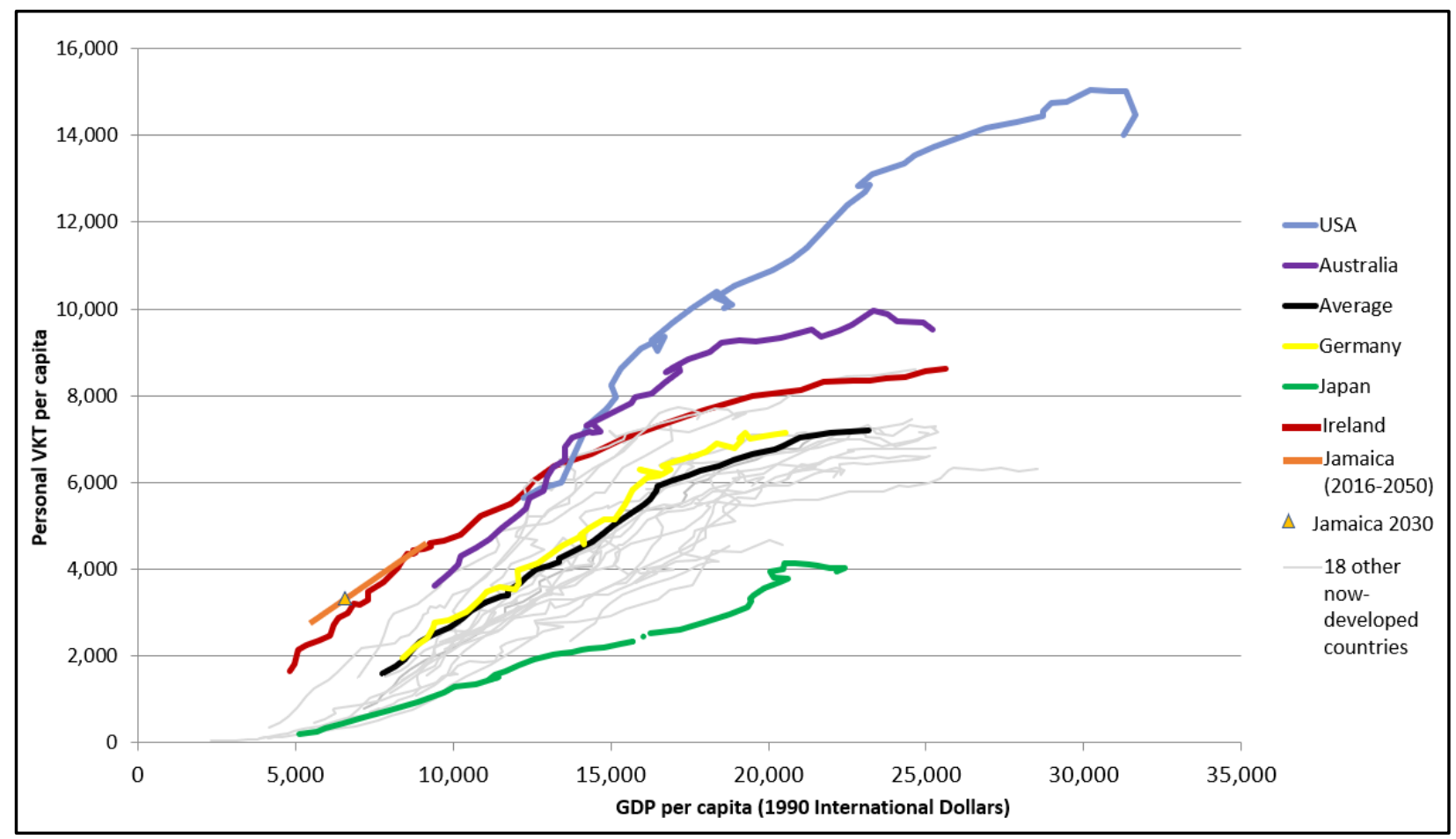

Figure 3. VKT of motorized passenger travel and per-capita GDP for 22 developed countries

Source: Based on data provided by the RAND Corporation and the Institute for Mobility Research collected as a part of the 2014 study (Ecola et al. 2014). Used with permission.

Since land transportation fuel use is most closely tied to VKT and VKT is most closely tied to per-capita GDP in international dollars (Ecola et al. 2014), a projection of Jamaica's per-capita

\footnotetext{
${ }^{1}$ International Dollars, also known as Geary-Khamis dollars, are based on purchasing power parity. 1990 International Dollars are used when comparing to the Ecola et al. (2014) study.
} 
GDP is needed. We used projections from the International Futures model created by the Pardee Center of the University of Denver. The model estimates Jamaica's per-capita GDP growing from to $\$ 8,400$ (in 2011 International Dollars) in 2016 to nearly $\$ 10,200$ in 2030 . Values were then converted from 2011 to 1990 International Dollars to be compatible with the data shown in Figure 3. Jamaica's 2016 starting point was then plotted on Figure 3 (in orange) at a per-capita GDP of $\$ 5,287$ and personal VKT of 2,887. This starting point has higher VKT than the other now-developed countries, largely because Jamaica has lower fuel prices and more car infrastructure than the other countries had at the time (some many decades ago) when they had a comparable per-capita GDP.

Using a simplified version of the process described in Ecola et al. (2014), the spatial dispersion of the population, car infrastructure, fuel prices, and availability of alternatives to driving were taken into account when estimating Jamaica's 2030 VKT. The result, as plotted on Figure 3, is an estimate that Jamaica's personal per-capita VKT in 2030 - when the per-capita GDP is estimated to be $\$ 6,573$ - would be $3,300 \mathrm{~km}$ per capita per year. When freight VKT are added back in at 14\% of total VKT, the end result is that total per-capita VKT increase from 3,357 in 2016 to 3,900 in 2030. This represents an average annual growth rate of $1.1 \%$.

The final step is to take population increase into account. We used projections from the United Nations World Population Prospects 2017 (United Nations 2017), which estimated Jamaica's population to increase from 2.88 million in 2016 to 2.93 million in 2030 . When combined with the per-capita VKT estimates, this indicates that total VKT in Jamaica will increase from 9.7 billion in 2016 to 11.4 billion in 2030, using a compounded annual growth rate of $1.2 \%$ (of which only $0.13 \%$ is due to population growth alone). This growth rate was applied to Jamaica's petroleum consumption and converted to GHG emissions to form the BAU scenario shown in Figure 4.

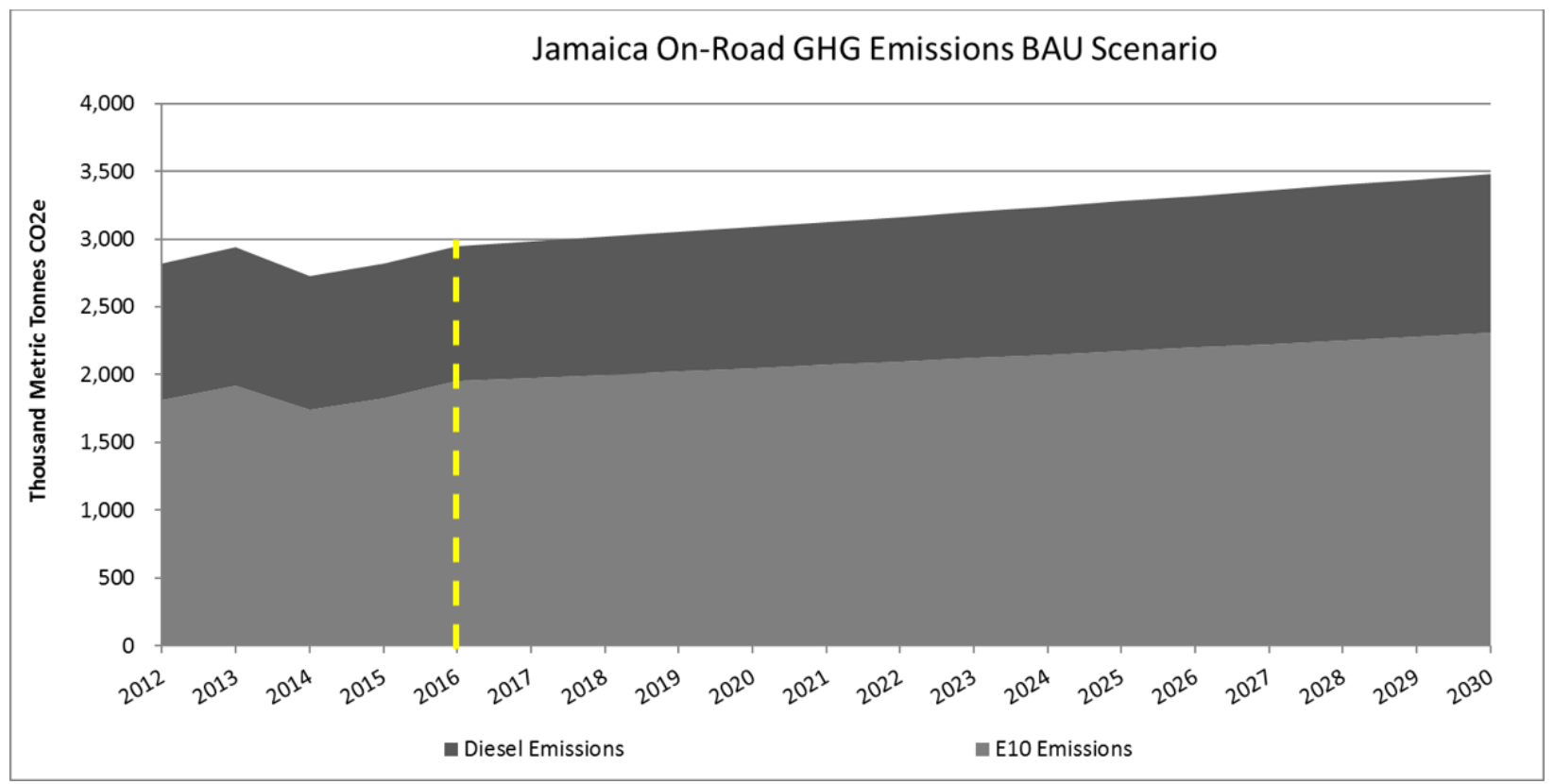

Figure 4. Jamaica on-road GHG emissions, BAU scenario 


\section{Charting GHG Reductions with Wedge Analysis}

The goal of reducing transportation petroleum use $10 \%$ below BAU by $2030^{2}$ is achievable if approached systematically. To do so, we break this overarching goal down into achievable subgoals through a "wedge analysis." The wedge analysis applies the BAU scenario developed in Section 3 and cumulatively reduces GHG emissions through subgoals (as shown in Table 3). Wedges are shaped as such because the fuel displacement resulting from each strategy grows as projects progress. For example, improvements to carpool platforms may initially result in modest petroleum displacement but then grow more substantial over time as the number of commuters using the platform increases. This analysis tool allows the user to assess the potential of various scenarios to achieve a $10 \%$ reduction from the BAU and to then formulate a plan of action. A scenario of reaching $80 \%$ GHG reduction by 2050 is modeled and tested in Appendix A. Model details are provided in Appendix B, Supplemental Model Details. A scenario to achieve the 10\% goal is outlined in Table 3, illustrated in Figure 5, and described in the text below.

Table 3. Subgoals, Their Predicted GHG Reduction, and Percent Contribution to Overall Goals

\begin{tabular}{lll}
\hline Subgoal (from 2030 BAU) & $\begin{array}{l}\text { Thousand Metric } \\
\text { Tons (TMT) } \mathbf{C O}_{2} \mathbf{e} \\
\text { Reduced }\end{array}$ & $\begin{array}{l}\text { Percent of } \\
\text { Overall } \\
\text { Goal }\end{array}$ \\
\hline $\begin{array}{l}\text { 9\% reduction in VKT of LDVs through walking, biking, using public } \\
\text { transit, ridesharing, and telecommuting }\end{array}$ & 206.8 & 58.6 \\
$\begin{array}{l}7 \% \text { improvement in fuel economy for new LDVs } \\
\text { All diesel contains 5\% biodiesel }\end{array}$ & 64.8 & 18.4 \\
$\begin{array}{l}\text { Traffic-flow is smoothed so that 1.5\% of road kilometers are } \\
\text { converted from city drive cycle to highway drive cycle }\end{array}$ & 57.9 & 16.4 \\
HDV idle time reduced 45 minutes per vehicle per day & 12.9 & 3.7 \\
$12 \%$ of new LDV purchases to be electric & 6.1 & 1.7 \\
\hline \multicolumn{1}{c}{$\mathrm{CO}_{2} \mathrm{e}-$ carbon dioxide equivalent } & 4.5 & 1.3 \\
\hline
\end{tabular}

${ }^{2}$ To match the goals for other sectors, as laid out in Jamaica's INDC 


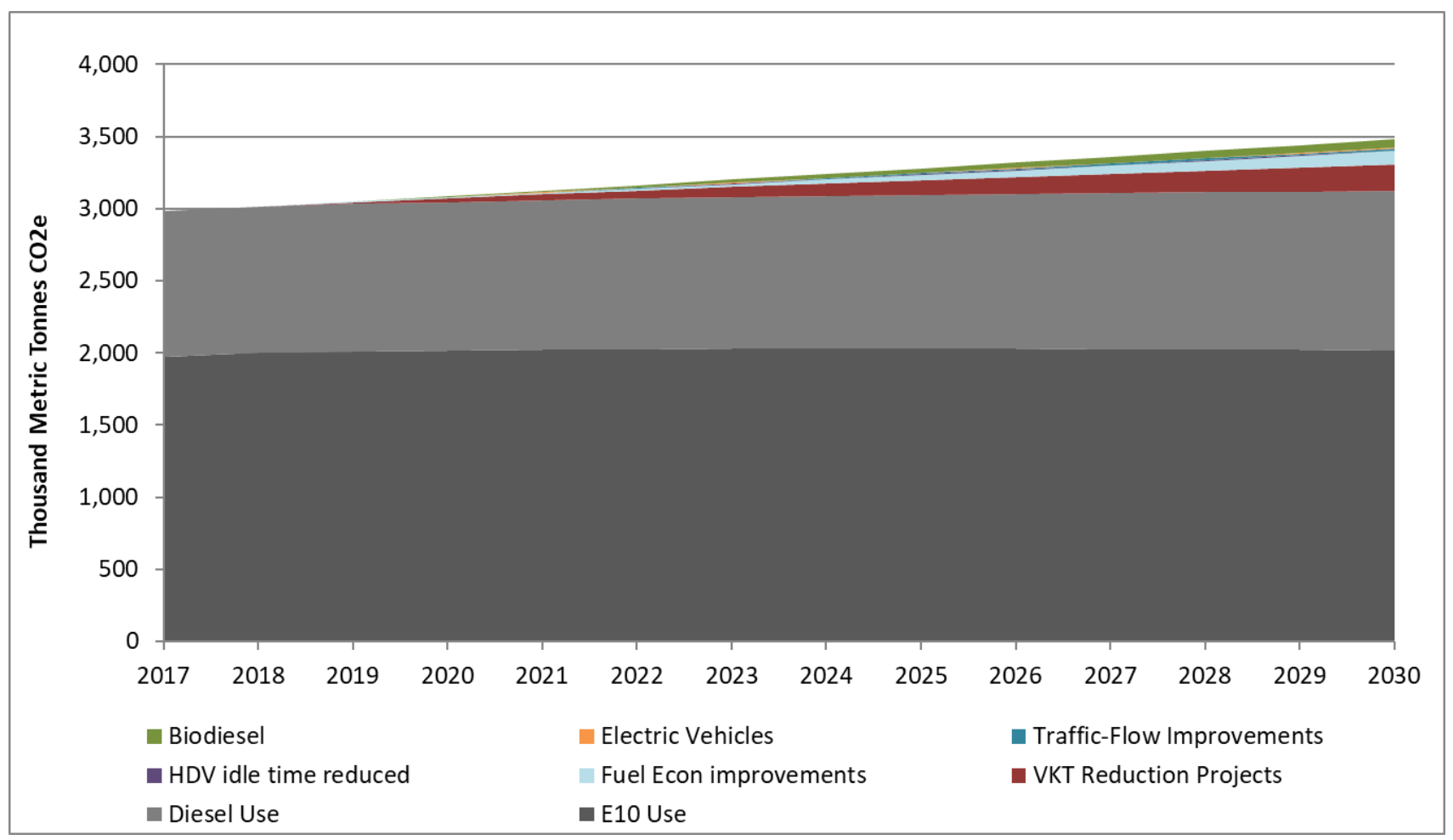

Figure 5. Reduction wedges to meet Jamaica's 10\% below BAU by 2030 goal

The subgoals reflected in Figure 5 were chosen because they align with Jamaica's resources and potential. Each subgoal is described below. The related projects to achieve the subgoals are introduced in Section 5.

1. Nine percent reduction in VKT of LDVs through walking, biking, using public transit, ridesharing, and telecommuting. This subgoal aims to retain and grow Jamaica's substantial ridership in modes other than private vehicles (Figure 6) as GDP per capita increases. Most of the GHG reductions from the VKT reduction subgoal will come from LDVs rather than MDV/HDVs, as MDV/HDV fleets are already fairly optimized to reduce operating costs related to $\mathrm{VKT}$. The VKT reduction wedge is the largest contributor towards the 2030 goal and is expected to provide over half of the overall petroleum-use reduction needed to achieve it. It should also be noted that most VKTreducing efforts also improve traffic flow and therefore improve vehicle fuel economy-an advantage not accounted for in the model. This category achieves over half of the overall 2030 goal. 


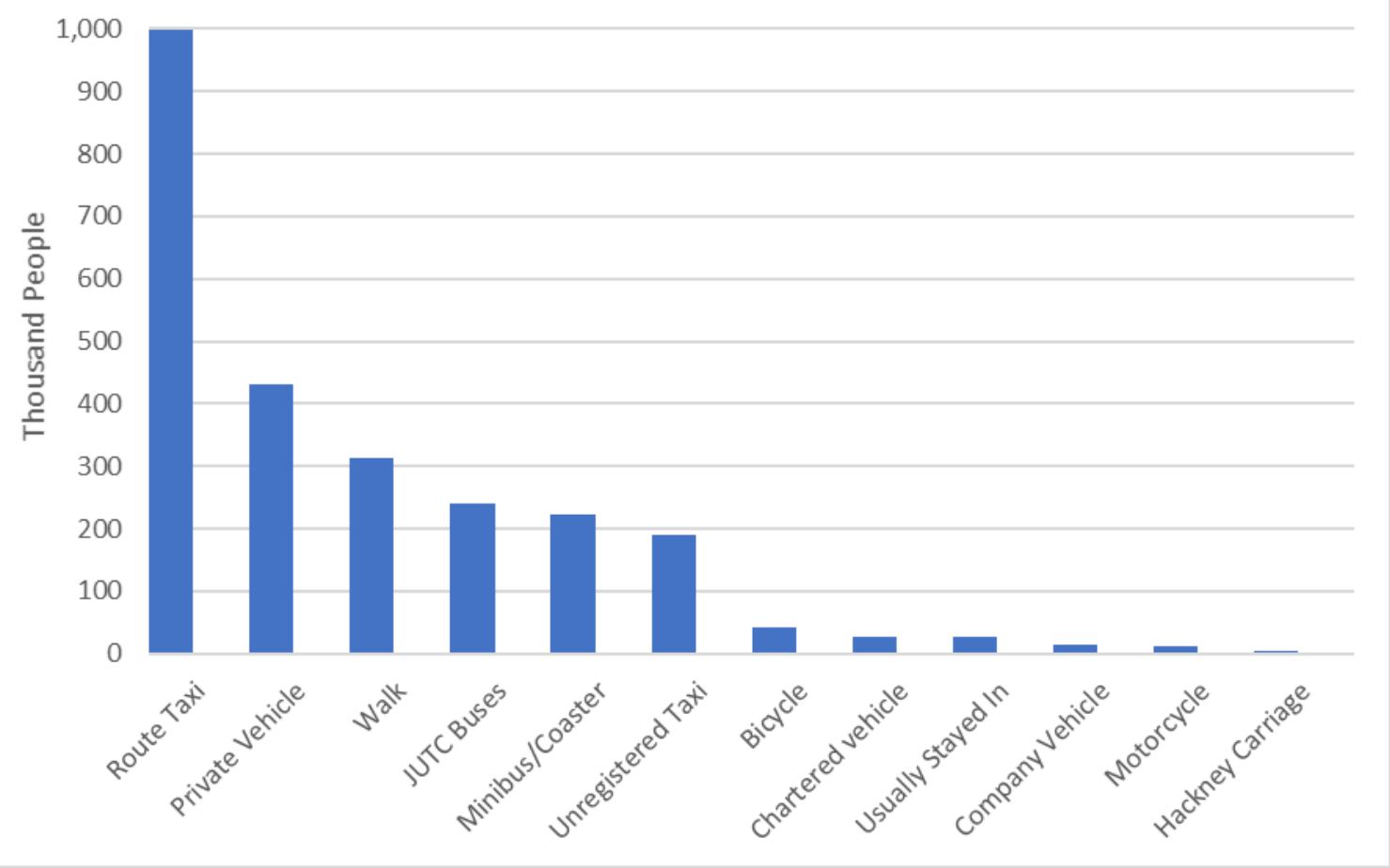

Figure 6. Number of Jamaicans by usual mode of transportation in Jamaica

Source: Statistical Institute of Jamaica (2017)

2. Seven percent improvement in fuel economy for new LDVs. This would bring the average fuel economy of new LDVs from $9.0 \mathrm{~L} / 100 \mathrm{~km}$ (per Table 2) to $8.4 \mathrm{~L} / 100 \mathrm{~km}$ in 2030. This subgoal is deemed realistic because $8.4 \mathrm{~L} / 100 \mathrm{~km}$ is slightly less efficient than the global average fuel consumption for new cars in $2005(8.3 \mathrm{~L} / 100 \mathrm{~km})$ and because it is much less than the 20\% improvement made between 2005 and 2013 in Organization for Economic Cooperation and Development markets (Global Fuel Economy Initiative 2016). Fuel economy improvement projects will provide over $18 \%$ of the needed petroleum use reduction to meet the 2030 goal. Therefore, this subgoal is the secondlargest contributor to the overall goal.

3. All road transportation diesel contains 5\% biodiesel (B5). This amount could likely be sourced from domestic waste oil and grease, which has more favorable economics than using virgin oils (Mandolesi de Araújo et al. 2013). Our calculations, shown in Appendix $\mathrm{C}$, estimate that there is enough used cooking oil (UCO) in Jamaica to supply $30 \%$ of B5 biodiesel needs and more than enough waste grease to supply the rest. UCO requires less processing than waste grease so should be utilized first. However, there are some hurdles to overcome in developing a collection system for these oils and greases and ensuring a quality product that will not harm engines. Some options for overcoming these hurdles are discussed in Section 5.3. Meeting the B5 subgoal would account for $16 \%$ of the overall 2030 GHG reductions.

4. Smooth traffic flow so that $1.5 \%$ of road kilometers, weighted by traffic volume, are converted from a city drive cycle to a highway drive cycle. Vehicles require more fuel to accelerate than to maintain a constant speed. Efficiency improvements are found when stop-and-go traffic patterns are replaced by more consistent speeds. Measures such as off 
ramps, traffic signal coordination, left-turn lanes, bus pull-offs, and throughways improve traffic flow and reduce GHG emissions. Such projects have a cumulative impact of converting part of a vehicle's drive cycle from the stop-and-go city drive cycle to the smoother highway drive cycle (as shown in Figure 7). The average LDV available for sale in the United States is $28 \%$ more efficient on the highway drive cycle than the city (www.fueleconomy.gov). However, this portion of the wedge does not take into account a potentially large, but so far unquantified, takeback effect whereby improved drive cycle and reduced drive times encourage people to drive more (Litman 2018). The achievement of this traffic-flow subgoal would account for $4 \%$ of the overall 2030 GHG reduction.

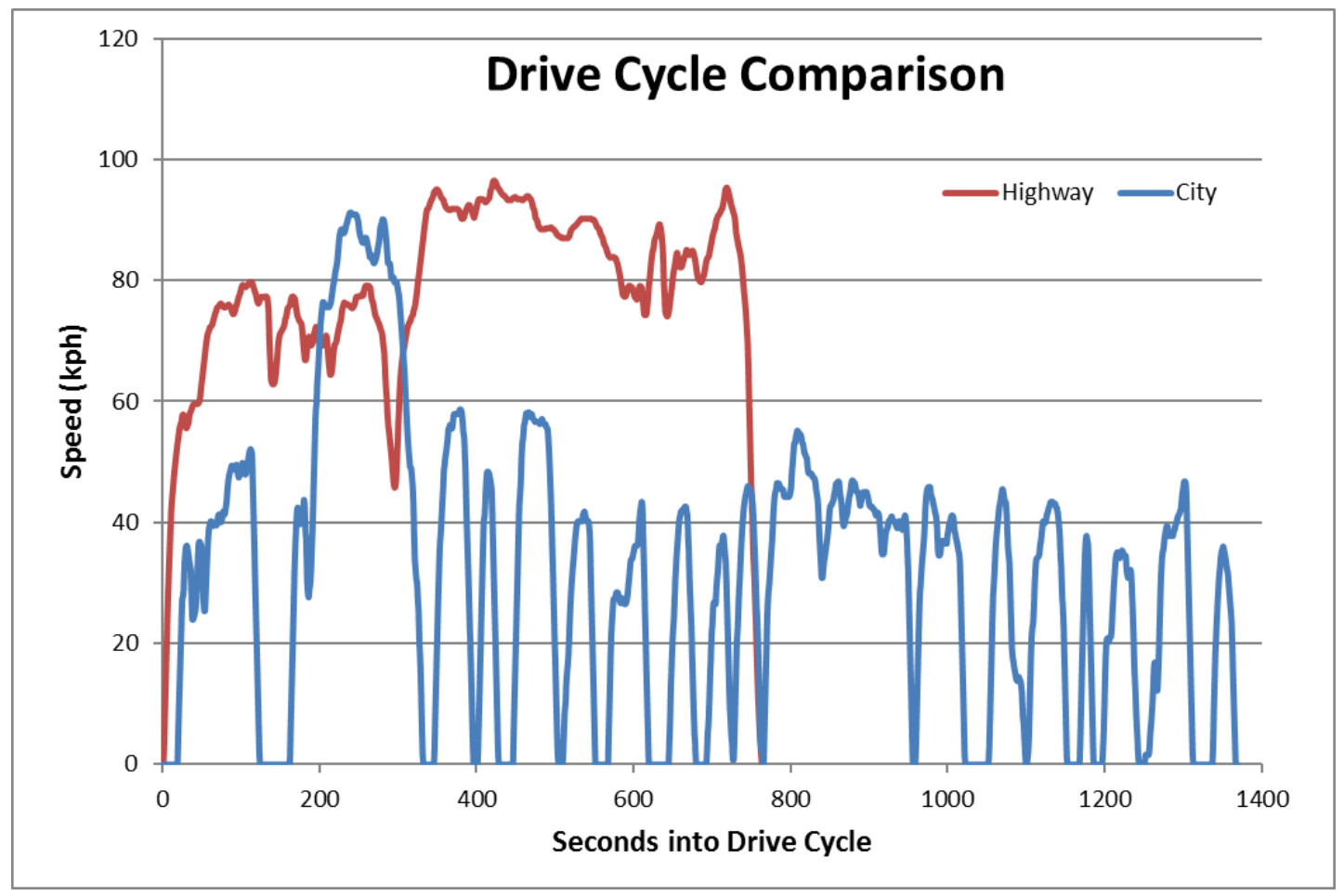

Figure 7. U.S. city and highway drive cycles

The average LDV achieves 28\% greater fuel economy on the Highway Drive Cycle (www.fueleconomy.gov)

5. Reduce HDV idle time by 45 minutes per day. When idling, HDVs use about 3.5 liters of diesel per hour, and LDVs use about 1.5 (Argonne National Laboratory 2018). This high consumption rate is because vehicle engines are not operating within their optimal range when idling. Auxiliary loads such as air conditioning or hydraulic lifts only require a fraction of the power that is delivered from an idling vehicle engine, so numerous technologies can enable these loads to be met with much lower fuel use. Such technologies include automatic engine shutoff and startup, storage cooling, auxiliary power units, electrified parking spaces, batteries, and driver training (Gaines and Weikersheimer 2016. The goal of 45 minutes is assumed to be a reasonable amount of idle time to cut, since in the mainland United States, $90 \%$ of trucks idle more than 48 minutes per day (Lutsey et al. 2004). Many cities around the world have successfully implemented idle bans that have reduced HDV idle time by more than 1 hour per day (Argonne National Laboratory 2018). Furthermore, Jamaica is at an advantage since its 
warm temperatures enable easy diesel startup without concerns of fuel gelling. This idle reduction (IR) subgoal contributes $2 \%$ to the overall $2030 \mathrm{GHG}$ emissions reduction.

6. Twelve percent of new LDV purchases to be electric by 2030 . We believe that this is a conservative target for two reasons. First, batteries are the dominant cost of electric vehicles (EVs), and these costs are dropping rapidly (Howell et al. 2016). Second, the efficacy of EVs as a GHG-mitigating technology largely depends upon the electricity mix. Figure 8 compares the carbon emissions of EVs, conventional vehicles, and a Prius HEV. The Nissan Versa and Nissan Leaf are the conventional and EV versions of the same vehicle model, respectively. Likewise, the Toyota Highlander and Tesla Model X are conventional and EV versions of sport utility vehicles (SUVs) of comparable size, respectively. Both EVs are lower-emitting than their conventional counterparts even with $0 \%$ renewable electricity. However, this chart also highlights the fact that HEVs such as the Toyota Prius have low emissions regardless of the electricity mix. Therefore, the EVpromoting policies and projects highlighted in Section 5.4, such as the toll road access, should be inclusive of HEVs, plug-in HEVs, and EVs, and the market can determine which is favored at any given time. The wedge analysis assumes that Jamaica meets its Intended Nationally Determined Contribution (INDC) goal of $20 \%$ renewable electricity production by 2030 (United Nations 2015). The EV subgoal will account for $1.3 \%$ of the 2030 GHG reductions.

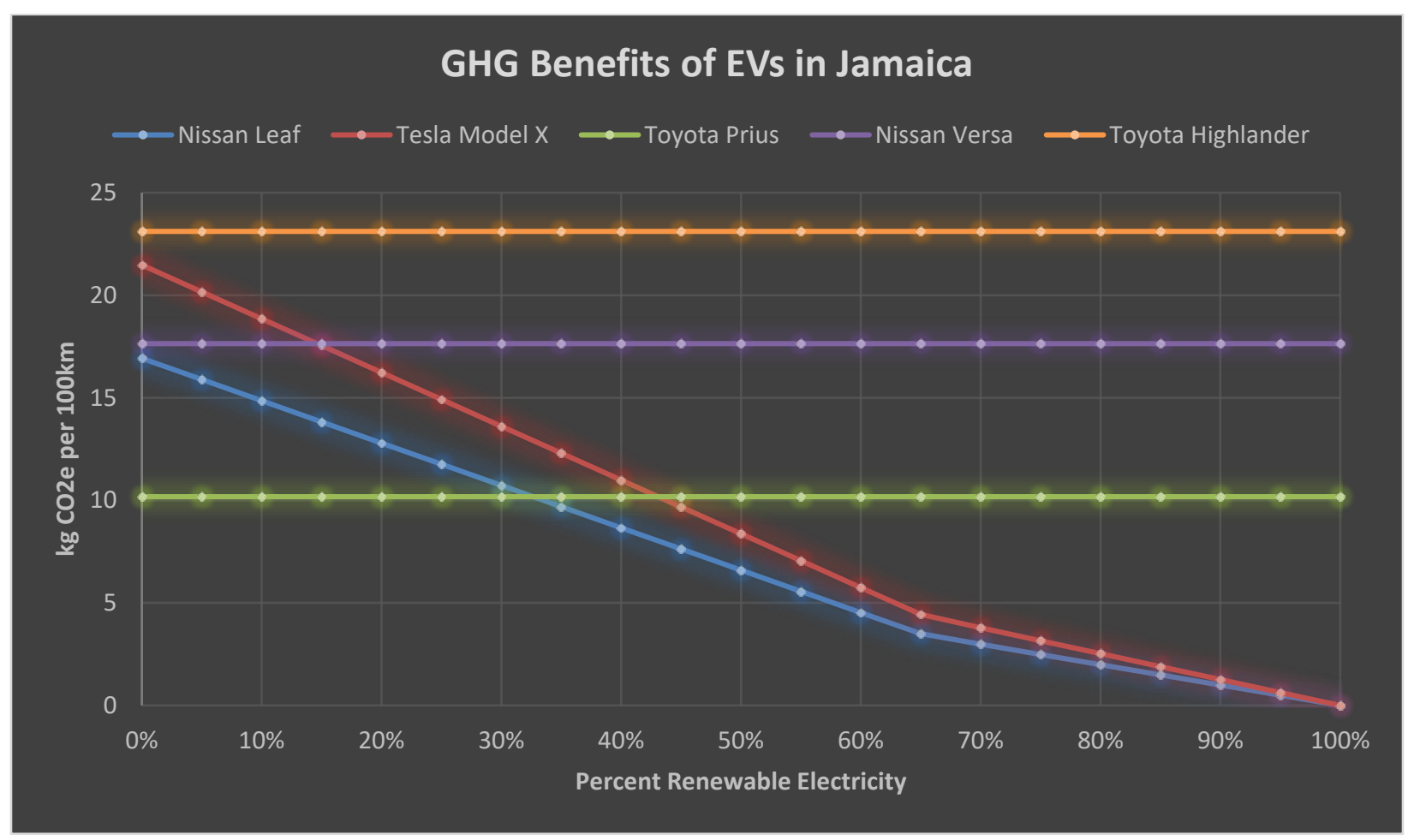

Figure 8. GHG emissions benefits of electric vehicles in Jamaica

Note: The EV emissions lines bend at $65 \%$ because at that point renewables start replacing natural gas instead of replacing fuel oil. 


\section{Policies and Projects to Reduce GHGs}

The first step on the path to reducing Jamaica's road transportation emissions was to calculate current emissions and project them to 2030. The next step was to apply Jamaica's INDC goal of 10\% below 2030 BAU scenario (United Nations 2015) to the transportation sector, down into the wedge-based goals listed in Figure 5. The third step is to identify specific policies and projects by which to achieve the wedge-based goals. This involved work by various agencies, organizations, and companies throughout Jamaica. A number of the projects have already been proposed or investigated by the GOJ. The fourth step is to prioritize the projects so that they may be pursued and funded in a strategic and systematic manner, as outlined in this section.

\subsection{Project Prioritization}

The proposed projects were prioritized in Table 4 based on the four factors bulleted below. Factors are currently generalized as green for good, yellow for average, and red for bad, but the labels could later be quantified into actual numbers. The ratings are all relative: projects with the worst ratings in any given category have already been removed from the list. Priority is given to the ranking on the left of Table 4, or to the top in the upcoming bulleted list. The four factors, in descending order of importance, are as follows:

- GHG Reduction Size represents the quantity of GHGs that a given project reduces by 2030. This is deemed the most important factor.

- Upfront Cost is the next most important factor. We chose to focus on upfront cost instead of lifecycle cost because the government can only take on a limited number of projects, and this limit is determined by their upfront cost. Many projects pay themselves off and are even cost-negative when viewing lifecycle costs. For divisible projects such as pedestrian paths or bus route expansion, Table 4 represents the cost of the less-expensive projects rather than the cost of all projects.

- $\quad$ Time Required to Implement considers how quickly the project can begin reducing GHG emissions. This rating considers one to two years as low, three to four years as medium, and five to 10 years as high.

- Ancillary Benefits reflects secondary benefits such as cost savings, time savings, convenience, safety, healthfulness, and equity associated with a project. These benefits usually lead to increased popularity from citizens (voters), which translates to political viability.

Future iterations of this plan could quantify the first three factors of this rating system into a measurement of metric tons GHG reduced per discounted dollar, where the discounted dollar takes the time to implement into account. However, such quantification is beyond the scope of the current project.

\subsection{Set Vehicle Taxes and Import Duty based on GHG Emissions}

Jamaica's carbon-based fuel taxes (Jamaica Ministry of Finance and the Public Service 2017) are a great first incentive for drivers to reduce their GHG emissions. However, there is evidence showing that drivers are even more responsive to up-front costs when purchasing vehicles than they are to lifecycle ownership costs (Sutherland 1991). Therefore, registration fees and import 
tariffs can pair nicely with the fuel taxes to be an effective mechanism by which to incentivize the purchase of more efficient vehicles.

Jamaica currently charges three fees on new vehicles: an import duty, the general consumption tax, and the special consumption tax. They are all based on a vehicle's value and therefore their primary incentive is for people to purchase less expensive vehicles. The import duty is $20 \%$ of value for cars, pickups, and SUVs, but only $10 \%$ for trucks and vans, thereby creating an incentive to purchase trucks and vans instead of smaller (presumably more efficient) cars, pickups, and SUVs. Furthermore, it disadvantages EVs by charging an import duty of $30 \%$. The general consumption tax is the same for all vehicles ( $16.5 \%$ if imported by individuals or $21.5 \%$ if imported by a dealer). The special consumption tax is less for diesel vehicles than for gasoline across the board, providing an incentive to purchase diesel vehicles. The special consumption tax increases with greater engine size within the car/SUV/pickup category, which incentivizes the purchase of more efficient vehicles over a limited range. Furthermore, the special consumption tax is $0 \%$ for highly efficient hybrids, EVs, and motorcycles. 


\begin{tabular}{|c|c|c|c|c|c|}
\hline Category & Policy Options / Projects & $\begin{array}{l}\text { GHG } \\
\text { Reduction } \\
\text { Size }\end{array}$ & $\begin{array}{l}\text { Upfront } \\
\text { Cost }\end{array}$ & $\begin{array}{l}\text { Time } \\
\text { Required to } \\
\text { Implement }\end{array}$ & $\begin{array}{l}\text { Ancillary } \\
\text { Benefits }\end{array}$ \\
\hline $\begin{array}{l}\text { Fuel } \\
\text { Economy }\end{array}$ & $\begin{array}{l}\text { Set vehicle taxes and import duty } \\
\text { according to GHG emissions }\end{array}$ & High & Low & Low & Med \\
\hline Biodiesel & Catalyze market for B5 from UCO & High & Low & Med & High \\
\hline EV & Allow EVs free access to toll roads & High & Low & Low & Low \\
\hline $\begin{array}{l}\text { Idle } \\
\text { Reduction }\end{array}$ & Idling limitations & High & Low & High & Med \\
\hline $\begin{array}{l}\text { VKT } \\
\text { Reduction }\end{array}$ & $\begin{array}{l}\text { Develop a Parking Management } \\
\text { Program for Kingston that focuses on } \\
\text { reducing VKT }\end{array}$ & High & Med & Low & High \\
\hline $\begin{array}{l}\text { VKT } \\
\text { Reduction }\end{array}$ & $\begin{array}{l}\text { Coordinate route taxis to enable higher- } \\
\text { capacity vehicles }\end{array}$ & High & Med & High & High \\
\hline $\begin{array}{l}\text { VKT } \\
\text { Reduction }\end{array}$ & $\begin{array}{l}\text { Track buses and show live transit } \\
\text { updates in Google Maps }\end{array}$ & Med & Low & Low & High \\
\hline $\begin{array}{l}\text { VKT } \\
\text { Reduction }\end{array}$ & $\begin{array}{l}\text { Pedestrian reflectors to improve safety } \\
\text { at night }\end{array}$ & Med & Low & Low & High \\
\hline $\begin{array}{l}\text { Fuel } \\
\text { Economy }\end{array}$ & $\begin{array}{l}\text { Fuel economy and fuel cost labeling } \\
\text { requirements }\end{array}$ & Med & Low & Low & Med \\
\hline $\begin{array}{l}\text { VKT } \\
\text { Reduction }\end{array}$ & $\begin{array}{l}\text { Safe passing rule for bikers and } \\
\text { pedestrians }\end{array}$ & Med & Low & Med & High \\
\hline $\begin{array}{l}\text { Traffic } \\
\text { Flow }\end{array}$ & Coordinate traffic signals & Med & Med & Low & High \\
\hline $\begin{array}{l}\text { VKT } \\
\text { Reduction }\end{array}$ & $\begin{array}{l}\text { Rumble strips to improve } \\
\text { pedestrian/biker safety }\end{array}$ & Med & Med & Med & High \\
\hline EV & $\begin{array}{l}\text { Install public EV chargers in strategic } \\
\text { locations }\end{array}$ & Med & Med & Med & Low \\
\hline $\begin{array}{l}\text { Traffic } \\
\text { Flow }\end{array}$ & $\begin{array}{l}\text { Left-turn lanes at key intersections to } \\
\text { improve traffic flow }\end{array}$ & Med & Med & High & High \\
\hline $\begin{array}{l}\text { Fuel } \\
\text { Economy }\end{array}$ & Motorcycle/scooter safety program & Low & Med & Low & Med \\
\hline $\begin{array}{l}\text { Traffic } \\
\text { Flow }\end{array}$ & $\begin{array}{l}\text { Bus and route taxi pull-offs to improve } \\
\text { traffic flow }\end{array}$ & Low & Med & Med & High \\
\hline
\end{tabular}

There are several ways that Jamaica could change its duties and taxes to encourage moreefficient vehicles while holding revenue even. The easiest would be to use the existing vehicle categorizations but simply charge higher rates for heavier vehicles or ones with larger engines and lower rates for smaller vehicles and engines. Both of these vehicle attributes are positively correlated with GHG emissions. Secondly, it could create a new system of categorization that more directly targets GHG emissions (which allows for alternative fuels). Numerous countries have implemented such registration fees that are based on carbon dioxide emissions or fuel consumption that can be emulated (Global Fuel Economy Initiative 2016). The most effective of 
these is the "feebate" (Mims and Hauenstein 2008) systems that actually pay people that register the most-efficient vehicles. These systems are particularly successful in part because they are politically more feasible.

- GHG reduction is very large. Based on the success of similar policies in other countries, this policy change could easily improve fuel economy by $10 \%$, which would result in a reduction of 66 thousand metric tons (TMT) carbon dioxide equivalent $\left(\mathrm{CO}^{2} \mathrm{e}\right)$.

- Upfront cost is considered low because the government already has enforcement and collection mechanisms, with supporting staff, in place.

- Time required to implement is considered low because if it is revenue-neutral, the policy could likely be updated quickly by the Tax Policy Development division of the Ministry of Finance. This is facilitated by the fact that necessary fuel economy data are collected and made available by European Union countries, Japan, the United States, and others (European Commission 2008; Mock 2013).

- Ancillary benefits are medium, and primarily consist of money savings for the drivers and the potential of increased revenues to the GOJ.

\subsection{Catalyze B5 Market}

Profit may be made from operating a program that collects UCO or waste grease and converting it to biodiesel. Therefore, it is recommended that the GOJ take steps to ensure price signals are passed to catalyze these viable markets. The first step is to ensure that UCO and waste grease are not dumped into sewers, where they do costly damage to water treatment systems and raise overall water treatment costs by an estimated 25\% (Paraiba et al. 2015). This requires a restriction on dumping oil and grease into drains or onto the ground, accompanied by adequate enforcement. The second step is to encourage vendors that specialize in waste oil and grease recycling to implement private collection systems with customers.

North Carolina does this by posting a contact list of such UCO recycling companies (N.C. Department of Environmental Quality 2019). The GOJ could commit to purchasing waste oil at a price equal to the cost savings from reducing damage to wastewater treatment facilities to create a floor price in the market. However, the UCO has much higher value as a fuel, so the next step would be to notify biodiesel producers of the opportunity and hold workshops where potential collection companies and biodiesel producers can discuss the logistics of Jamaican markets. Many UCO collection companies are already integrated with biodiesel production companies. Finally, the GOJ should adopt or develop a biodiesel standard to ensure that the product will not damage engines or customer trust in biodiesel. Two standards that are commonly used as a basis for new standards are ASTM D975 (used in the United States for diesel with up to 5\% biodiesel [B5]) and EN590 (used in the European Union for blends up to 7\%) (Jääskeläinen 2009).

- GHG reduction is very large. Using B5 in place of diesel for all road transportation should reduce GHG emissions by 58 TMT per year by 2030.

- Upfront cost is low because the government is simply facilitating the private sector to set up a viable market in UCO collection and biodiesel production. 
- Time to implement is considered medium because it could take a few years to get people to recycle their UCO, build a biodiesel production facility, and set standards that ensure the quality of biodiesel.

- Ancillary benefits are high because this project reduces damage to water treatment facilities and creates numerous jobs in the UCO recycling and biodiesel production systems. Furthermore, biodiesel improves the lubricity and cetane of diesel fuel, causing the engine to operate better and last longer (Alternative Fuels Data Center 2018).

\subsection{Allow EVs Free Access to Toll Roads}

Jurisdictions that allow EVs to use high-occupancy vehicle lanes typically see higher rates of EV purchases. U.S. states with high-occupancy vehicle lanes and EV exemptions have $15 \%$ greater EV purchase rates ( $8 \%$ for plug-in HEVs) than those without, even when controlling for 12 other factors (Narassimhan and Johnson 2018). It is reasonable that allowing EVs free use of toll roads would also act to incentivize EV purchases. This impact could be large in Jamaica since it has three major toll roads (A1, T1, and Port Kingston Causeway) and a mandate to increase this number of toll roads, and the tolls are expensive when compared to the per-capita GDP (Toll Authority of Jamaica 2018).

- The GHG reduction from this policy is considered large. This policy could be the dominating driver in achieving the goal of EVs comprising $12 \%$ of all LDV sales by 2030, which would reduce Jamaican GHG emissions by 4.5 TMT.

- Upfront cost is predicted to be low. The toll authority could likely add this clause to existing contracts with vendors, possibly at a cost to GOJ. The cost would likely be low given the current low penetration of EVs in Jamaica.

- Time required to implement would be short because no construction is needed, and it could likely be implemented by the Toll Authority rather than requiring legislation.

- Ancillary benefits would be low. The only major benefit outside of GHG reduction would be air quality improvement and energy independence once a larger share of electricity is produced from renewables. This policy would be slightly regressive since EVs tend to be more expensive vehicles.

\subsection{Limit HDV Idle Time with the Help of IR Technologies}

As explained in the wedge analysis section, it is likely that most HDVs in Jamaica idle more than 45 minutes every day, and they can see substantial cost savings by limiting their idle time. Therefore, a five-pronged approach could work well for Jamaica.

1. Reduce idling in the GOJ fleet to lead by example, test IR technologies, and develop expertise to share with other fleet managers.

2. Meet with managers of major county, local, and private fleets to explain the cost benefits of IR and the various technologies available that enable their vehicles to perform necessary functions while stationary (U.S. Environmental Protection Agency 2018). The Idling Reduction Savings Calculator developed by Argonne National Laboratory (2018) could facilitate such conversations. Also, introduce fleet managers to upcoming antiidling laws and signage to help convince their drivers to participate. 
3. Pass IR laws, drawing from the experience of other governments that have passed such laws (U.S. Environmental Protection Agency 2006).

4. Post signage in key idling areas reminding drivers of idle restrictions and calling on fellow citizens to help enforce restrictions to improve air quality (see Figure 9). Schools are an important place to post such signs as children are particularly vulnerable to the health effects of emissions.

5. Enforce idle restrictions by responding to complaints and patrolling areas with signage.

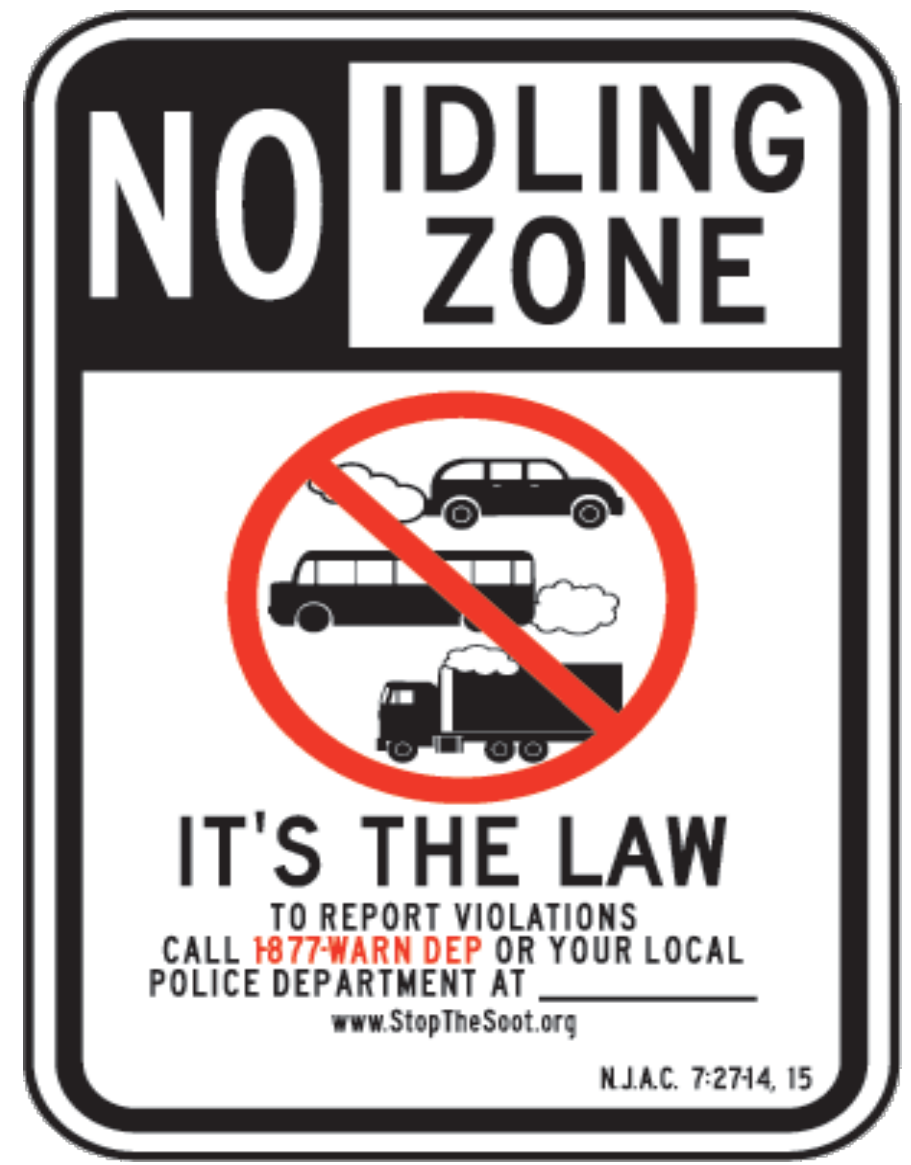

Figure 9. Sign marking "no idling zone" with number to report infractions

Source: N.J. Department of Environmental Protection (2015)

This five-step strategy ranks well in Table 4, per the following assessment.

- GHG reduction is estimated to be large, assuming that HDV idle time and fuel consumption are similar to their counterparts in the United States. If they are, then $90 \%$ of HDVs idle more than 45 minutes a day (Lutsey et al. 2004), and they consume an average of $3.5 \mathrm{~L}$ /hour (Argonne National Laboratory 2018). Assuming these estimates are applicable to Jamaica and the goal of 45 minutes/day is achieved, this program is estimated to reduce over $6 \mathrm{TMT} \mathrm{CO}_{2}$ e. Furthermore, this program is likely to spread to LDVs and achieve even greater GHG savings. 
- Upfront cost is estimated to be low. IR equipment is generally reasonable, and most fleets will pay it off quickly. The most substantial cost will be enforcement, but this cost is greatly reduced by persuading citizens to contact authorities when they witness violations. Creating a convincing roll-out strategy is vital to ensuring that citizens recognize the importance of clean air and the impact IR can have upon air quality.

- Time required to implement the plan is high because each step is constrained by the steps before it. Furthermore, legislative action would be needed.

- Ancillary benefits are medium. IR reduces local air pollution, which is especially beneficial around areas with a high concentration of children (who are particularly vulnerable to air pollution) such as schools. Fleets should also see financial benefits due to the reduced fuel costs and maintenance costs (Gaines and Weikersheimer 2016).

\subsection{Develop a Parking Management Program for Kingston that Focuses on Reducing VKT}

Parking management programs can be very effective ways to reduce VKT. The most effective programs place a price on parking (a valuable commodity), allowing commuters to account for the price of parking when deciding how to travel to congested areas. This makes alternatives such as ridesharing, bus, biking, and walking much more economically attractive. Furthermore, right-priced parking can greatly reduce the VKT spent "cruising" for parking (Shoup 2006). This is a substantial benefit, as 16 studies of cruising in urban neighborhoods found an average of $30 \%$ of traffic were cruisers, and their average time spent cruising for parking was more than 8 minutes (Shoup 2006). By reducing "minimum parking requirements" for developers and improving parking utilization rates, cities can develop in a more condensed way that is conducive to walking and biking (Litman 2016a). Therefore, the National Environment and Planning Agency should consider alternative modes of transportation and possibly adjust the minimum parking requirements listed in its Development and Investment Manual (National Environment and Planning Agency 2007).

To enable Kingston to reduce its parking in densely populated areas, they can provide strategic parking lots in bottlenecks around Kingston where commuter traffic condenses and becomes more congested. These strategic parking lots are places where buses and rideshares can quickly and frequently pick up many passengers and take them to various destinations in Kingston. These lots could initially boost ridership of route taxis, but as they become more popular, they will provide a critical mass of passengers for buses to leave more frequently and have a greater variety of routes, enabling the bus system to out-compete route taxis in many locations entering Kingston. Similar strategic parking lots known as "Park \& Rides" have been very successful throughout urban areas in the United States.

- GHG reduction is high. Parking policy has been identified as a highly effective way to reduce traffic and VKT (Cairns et al. 2008). Therefore, a sound parking management program would have a very large impact on GHG emissions.

- Upfront cost is medium. A parking management program should incur lower costs than increasing parking capacity, which is the route that many cities take when their vehicle populations increase. Furthermore, substantial revenue can be generated by a parking management program that can offset upfront costs. Some of the costs to be incurred are 
staff and equipment needed for parking enforcement, equipment needed to coordinate vehicles to find under-utilized parking spaces, and strategic parking lots (which will probably be built in locations with lower property values than unstrategic lots in downtown Kingston). Another cost to be considered is the cost of alternatives to parking, such as bicycle paths and additional buses.

- Time required to implement is considered short since Kingston is already taking steps toward a parking management program (Jamaica Observer April 15, 2015) and because new lots can be built incrementally.

- Ancillary benefits are high. They include better allocation of parking spaces to higherpriority use such as delivery vehicles, short errands, and drivers that carpooled. All attributes that reduce VKT also will reduce traffic congestion and accidents. A smart parking management program can also greatly reduce building development costs, increase the flexibility of land use, and make housing more affordable (Litman 2016b).

\subsection{Coordinate Route Taxis to Enable Higher-Capacity Vehicles}

Route taxis were the primary means of transportation for 39\% of Jamaicans in 2011 (Statistical Institute of Jamaica 2011). By driving multiple people along a similar route, these taxis limit the number of single-occupancy vehicles on the road, which reduces GHG emissions. The parking legislation outlined in Section 5.6 will likely make route taxis more attractive to commuters who do not wish to pay for parking in the city. To increase the GHG reductions and ancillary benefits of route taxis, steps should be taken to enable them to graduate in size from sedans carrying three to four passengers to minivans and full-sized vans that carry up to 15 passengers. Table 5 gives an example of the significant fuel reductions implicit with increasing the capacity of route taxis. Economic factors are already favoring larger vehicles (since the driver can make much more per hour carrying more passengers) so the logistical challenges need to be addressed. Steps to reduce these logistical challenges are as follows.

1. Remove the restriction that route taxis cannot have more than 10 seats (Transportation Authority 2013).

2. Formalize routes by creating maps and publishing them online so that people will know the availability of route taxis near them. Such maps can be crowd-sourced such as the one being created for the colectivos in Mexico City (Mapatón 2016). Coordinate with Jamaica Urban Transit Company (JUTC) and add routes that help solve their "first and last mile" challenge (Mass Transit Magazine August 15, 2016) by linking route taxis between bus stops and passengers' homes.

3. Increase predictability and usability of route taxis by developing a schedule and coordinating timing. There is currently a financial incentive for route-taxis to wait until they are full before they leave the parking lot. This delays the departure of the route taxi, making it much less convenient for those boarding it later in its route. If route taxis were required to adhere to a departure schedule, this perverse incentive could be overcome, and reliability would be increased.

4. Identify slots in schedules that can use vehicles with additional capacity and notify vehicle owners that these slots will be transitioned to vans and minivans. This would likely require a survey of drivers that tracks back to their scheduled departures. 
5. Work with vehicle dealerships to identify route taxi owners in good standing and extend low-interest loans for the purchase of vans and minivans.

Table 5. Fuel Economy Examples for High-Capacity Route Taxis in L/100 passenger-km

\begin{tabular}{lllll}
\hline Route Taxi (2010) & $\begin{array}{l}\text { Vehicle Fuel } \\
\text { Economy } \\
\text { (L/100 km) }\end{array}$ & $\begin{array}{l}\text { Number of } \\
\text { Passengers }\end{array}$ & $\begin{array}{l}\text { Passenger Fuel } \\
\text { Economy (L/100 } \\
\text { passenger-km) }\end{array}$ & $\begin{array}{l}\text { \% Improvement } \\
\text { from Four- } \\
\text { Passenger } \\
\text { Corolla }\end{array}$ \\
\hline $\begin{array}{l}\text { Toyota Corolla } \\
\begin{array}{l}\text { Toyota Sienna } \\
\text { minivan }\end{array}\end{array}$ & 9.0 & 4 & 2.3 & $0 \%$ \\
Nissan NV3500 van & 11.8 & 7 & 1.7 & $25 \%$ \\
\hline
\end{tabular}

This strategy ranks well in Table 4, per the following assessment:

- GHG reduction is high because 39\% of Jamaicans utilize route taxis as their primary form of transportation. Furthermore, the per-passenger efficiency improvement could be significant, per Table 5.

- Upfront cost is medium because government assistance would likely be needed to cover mapping routes, scheduling, website creation and maintenance, and coordinating in the route taxi terminals. Small vehicles will be replaced at the end of their useful life so only the incremental cost of the larger vehicles can be attributed to the project costs.

- Time required to implement would be high because of the multitude of routes, schedules, and vehicles that would need to be optimized. Coordinating route taxis is particularly time-intense because there are thousands of participants that are not tightly organized through the All-Island Route Taxi Association and its 28 regional associations.

- Ancillary benefits would be high because condensing passengers into fewer route taxis could substantially reduce traffic congestion and accidents while improving air quality.

\subsection{Track Buses and Show Live Transit Updates in Google Maps}

The JUTC has uploaded its schedules onto Google Maps to make its bus system more userfriendly and accessible. The next step toward greater predictability of buses is to add live transit updates for Kingston. This lets riders know exactly when their bus is going to arrive, as shown in Figure 10. This is best done through Transport Tracker (directions are on the Transport Tracker Solutions website [Google "The Transport Tracker Solution"]). Given that the number of smart phone users on one of Jamaica's two service providers surpassed 1 million in January 2015 (Jamaica Observer January 10, 2015), it is reasonable to assume that a large portion of Jamaica's 2.9 million citizens now have a smart phone. Bus updates can be viewed on computers as well. 


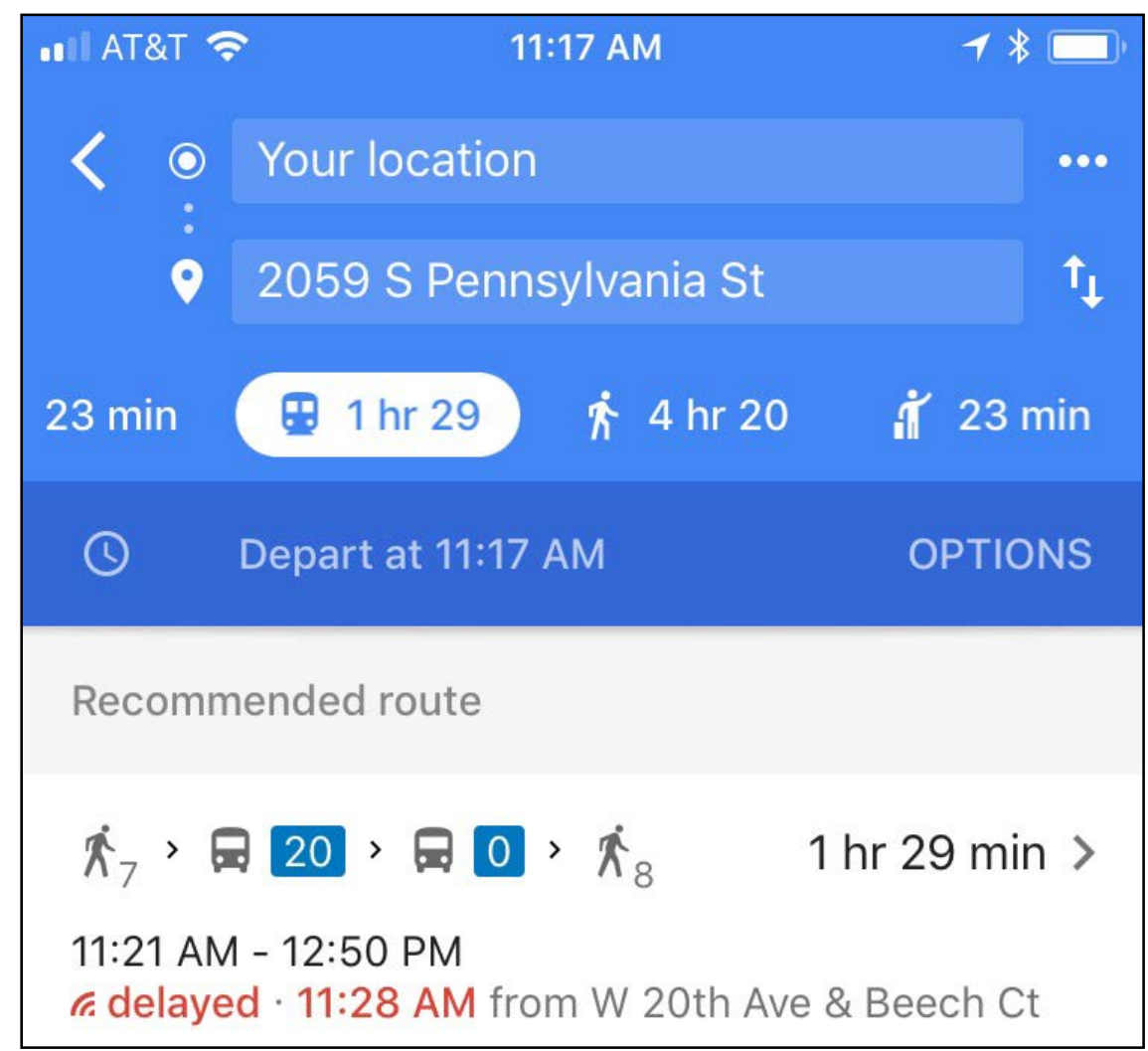

Figure 10. Smart phone screen shot displaying live transit updates on Google Maps

- GHG reduction is medium. Jamaica's BAU case assumes that its bus ridership rates will decrease as the country develops. This is what other countries have experienced; the trend is driven by inconvenience and unpredictability associated with riding the bus. The JUTC can retain riders by increasing convenience and predictability even as its wealth and ability to purchase private vehicles increases.

- Upfront cost is low. It consists of an Android smart phone used as the locator device in each bus (old phones are fine), a monthly service plan, a Firebase Realtime Database, and a developer on staff to develop this capability and trouble shoot when something goes wrong. The necessary code is open sourced and free on GitHub (Google "Transit").

- Time required to implement is low. Arranging for the purchase of the phones, installation, setup for the database, and launching the capability in Google Maps should take a few months.

- Ancillary benefits are high. Live transit updates will save riders considerable time and stress. By increasing ridership, traffic will also be reduced, along with the associated GHG emissions. 


\subsection{Provide Pedestrians and Cyclists with Safety Reflectors and Lights}

VKT will increase so long as pedestrians feel safer in cars than on foot. Travelling on foot at night is a particular concern, as $75 \%$ of accidents in the United States that result in a pedestrian casualty occurred in the dark (National Center for Statistics and Analysis 2018). Much of Jamaica's population lives in areas with inadequate street lighting. Various pilot programs to distribute reflectors or lights to school children have proven effective at mitigating accidents (World Health Organization 2013). Studies have identified that reflector vests are the most effective option for increasing the visibility of cyclists to drivers (Wood et al. 2012). Other considerations include:

- GHG reduction is medium. While the distances that people usually travel by foot are relatively small, each kilometer of vehicle travel replaced by foot travel results in a $100 \%$ reduction in GHG emissions. This is the same for cycling, although the distances covered are longer. More than $12 \%$ of Jamaicans walk as their primary means of transportation and $2 \%$ bicycle (Statistical Institute of Jamaica 2011). If improving pedestrian and cyclist safety could retain or increase this rate of walking, it could have a substantial impact on GHG emissions.

- Upfront cost is low. Purchasing reflective bags or clothing for school children is significantly less expensive than funding most projects involving road infrastructure or vehicle purchases. Furthermore, once the advantages of reflectors and lights become apparent to pedestrians, at a certain point it is possible they may purchase their own reflective gear and project maintenance costs would be minimal.

- Time required to implement is low. Reflectors and lights can be purchased quickly. However, a robust outreach campaign preceding the distribution of equipment distribution is recommended in order to educate pedestrians and cyclists about the value and use of the equipment.

- Ancillary benefits are high. Reflective equipment can save lives and protect the health of both children and adults. Furthermore, increases in pedestrian and cyclist activity are inversely related to traffic congestion and air pollution.

\subsection{Lower-Priority Policies and Projects}

The projects listed above either ranked high on GHG reduction or ranked high on all other attributes, making them the higher-ranking half of all proposed projects. As such, these projects were discussed in greater depth. This section gives a brief overview of the second half of the projects. Despite being covered in less depth, these projects could be quicker and easier to implement or might deserve consideration for reasons not listed in Table 4. Such considerations could include having a champion that pushes their implementation before other projects. The remaining projects include:

1. Fuel economy and fuel cost labeling requirements. Stickers on vehicles at dealerships with the estimated fuel economy or annual fuel cost of the vehicle enable consumers to take the economics of fuel economy into account at the point of purchase. IEA 2015 (Mock 2013) compares various fuel efficiency labelling schemes from around the world 
and provides best practices that can be applied to Jamaica. Using fuel economy on the Japanese test cycle would be a good start since most of Jamaica's vehicles are from Japan and the data are readily available. However, to maximize accuracy, Jamaica could develop its own test drive cycle, perhaps with the DRIVE tool (National Renewable Energy Laboratory 2015).

2. Safe passing rule for bikers and pedestrians. A minimum passing distance law sends a signal that pedestrians and bikers have the right to be on the road and that it is the responsibility of drivers to avoid hitting them. Of course, the law is only effective if police actively enforce it. The League of American Bicyclists developed a model safepassing law (League of American Bicyclists 2019) to help municipalities and countries develop effective laws. Much can also be learned from existing policies for pedestrian and bicyclist safety, as reviewed by the International Technology Scanning Program 2010 (U.S. Department of Transportation 2010).

3. Coordinate traffic signals. Mis-timed traffic signals have been identified as a cause of undue congestion in Kingston (Saunderson 2017). Signal coordination systems have the potential to improve traffic flow. The amount of fuel saved and GHGs reduced are dependent on many factors. The software SimTraffic (Cubic Trafficware 2019) was created to account for all those factors and estimate GHGs reduced. It is recommended that Kingston's most problematic signals be modeled in SimTraffic and the results be used to strategically replace signals that can be coordinated through a system such as Trafficware.

4. Rumble strips to improve pedestrian/biker safety. As most countries develop, they initiate a negative feedback loop. Cars are prioritized, VKT increase, pedestrian and biker safety decrease, which encourage travel by car instead of walking or biking. Jamaica should safeguard pedestrian and biker space to preempt this feedback loop. Rumble strips are a relatively inexpensive and effective way to keep drivers off the shoulder of the road, providing pedestrians with an assurance of safety. In areas where the road is too narrow, "sharrows" (National Association of City Transportation Officials undated) reserve space for bikers and increase driver awareness. Two helpful resources are the U.S. Federal Highway Administration's guide for installing rumble strips (U.S. Department of Transportation 2016) and the World Health Organization's road safety manual for decision makers (World Health Organization 2013).

5. Install public EV chargers in strategic locations. One of the main barriers to EV purchases is range anxiety, which can be ameliorated by highly visible public charging stations. In the United States, the relationship is that one additional charger per driving population of 100,000 correlates to a $3.1 \%$ increase in EV purchases (Narassimhan and Johnson 2018). Therefore, to increase EV purchases, Jamaica should install chargers along highly trafficked roads and promote them with ample road signage.

6. Add left-turn lanes at key intersections to improve traffic flow. Jamaica has many roads where vehicles turning left clog a lane of the intersection and stop vehicles that are going straight. Many vehicles could flow through the intersections unimpeded if the vehicles turning left had their own lane. An assessment should be done by the National Works Agency to determine which intersections have the most left-turners and lanes added systematically as resources allow. 
7. Create a motorcycle/scooter safety program. Motorcycles in the United States achieve an average fuel economy of 5.4 L/100 km (U.S. Department of Transportation 2018).

Assuming Jamaican motorcycles are as efficient, increasing motorcycle ridership could greatly improve overall fleet fuel economy. One of the most important things a government can do to increase motorcycle ridership is to improve the safety of riders. Fortunately, many Departments of Transportation worldwide have implemented programs to improve motorcycle safety to serve as examples. Five of the most proactive programs have been implemented in France; Ireland; Bogota, Colombia; and the state of Florida. The Florida Motorcycle Safety Strategic Plan (Florida Department of Transportation 2016) serves as a great example for Jamaica.

8. Build bus and route taxi pull-offs to improve traffic flow. When buses and route taxis stop in the road, they stop many cars behind them. This has a significant negative effect on the efficiency of the traffic flow. Analysis should be done by the National Works Agency on where this is happening the most often, and pull-offs should be added. 


\section{Conclusion}

Reducing Jamaica's GHG emissions by $10 \%$ below the 2030 BAU scenario is quite possible for the road transportation sector if approached systematically. The necessary data to define a transportation system were tracked (in the case of fuel use) and derived from several sources (in the case of vehicle stock and VKT). The BAU 2030 scenario was derived based on VKT increases seen in other countries as they developed. The $10 \%$ goal was then allocated to subgoals of GHG reduction, with the largest share $(59 \%)$ to be achieved by VKT reduction projects, then $18 \%$ from fuel economy improvement, $16 \%$ from B5 biodiesel, $3.7 \%$ from traffic-flow improvements, and 3\% split between IR and EVs. A path to achieve the subgoals was then charted out by a series of policies and projects that have track records of achieving GHG reductions in several other countries throughout the world. These projects could achieve the $10 \%$ GHG reduction goal and provide many co-benefits, including traffic reduction, air quality improvements, cost savings, and safety improvements. 


\section{References}

Ahrens, Ronald. 2010. “3 Teams Win Automotive X Prize.” New York Times, September 16, 2010. https://www.nytimes.com/2010/09/16/automobiles/16WINNERS.html

Alternative Fuels Data Center. 2018. "Biodiesel Benefits and Considerations." Washington, DC: U.S. Department of Energy. https://www.afdc.energy.gov/fuels/biodiesel benefits.html

Alternative Fuels Data Center. 2014. "Vehicle Weight Classes \& Categories." Washington, DC: U.S. Department of Energy. https://www.afdc.energy.gov/data/10380

ArcGIS. 2013. “Jamaica Average Household Size.” Last updated April 11, 2018. https://www.arcgis.com/home/item.html?id=0f482f4fc6db45678066f59ac87eaf70

Argonne National Laboratory 2018. "Idling Reduction Savings Calculator, Background Data." www.anl.gov/sites/www/files/2018-02/idling_worksheet.pdf

Argonne National Laboratory. 2018. IdleBase, Engine Idling Laws and Ordinances for All Classes of On-Road Vehicles. http://cleancities.energy.gov/idlebase

Biodiesel. 2012. "OEM Statement and Resources. Automakers' and Engine Manufacturers' Positions of Support for Biodiesel Blends." http://biodiesel.org/using-biodiesel/oeminformation/oem-statement-summary-chart

Bloomberg New Energy Finance. 2018. Electric Buses in Cities - Driving Towards Cleaner Air and Lower $\mathrm{CO}_{2}$. https://data.bloomberglp.com/bnef/sites/14/2018/05/Electric-Buses-in-CitiesReport-BNEF-C40-Citi.pdf

Bloomberg New Energy Finance. Electric Vehicle Outlook 2018. https://about.bnef.com/electricvehicle-outlook/

Cairns, S., L. Sloman, C. Newson, J. Anable, A. Kirkbride, and P. Goodwin. 2008. "Smarter Choices: Assessing the Potential to Achieve Traffic Reduction Using 'Soft Measures'."

Transport Reviews, 28:5, 593-618. https://www.tandfonline.com/action/showCitFormats?doi=10.1080\%2F01441640801892504

Capterra. "Route Planning Software." Accessed November 2018 at https://www.capterra.com/route-planning-software/

Cubic Trafficware. 2019. "Syncro® 10 Plus SimTraffic - Signal Timing and analysis Software." Sugarland, TX: Cubic Trafficware. https://www.trafficware.com/synchro.html

Davis, Stacy C., Susan W. Diegel, and Robert G. Boundy. 2013 Transportation Energy Data Book: Edition 32. Oak Ridge National Laboratory, Report No. ORNL-6989. https://info.ornl.gov/sites/publications/files/Pub44660.pdf 
Ecola, Liisa, Charlene Rohr, Johanna Zmud, Tobias Kuhnimhof, and Peter Phleps. 2014. The Future of Driving in Developing Countries. Santa Monica, CA: RAND Corporation. www.rand.org/t/rr636.

European Commission. 2008. "Car Labeling." Directive 1999/94/EC of the European Parliament and of the Council of 13 December 1999, as amended 22 October 2008.

https:/ec.europa.eu/clima/policies/transport/vehicles/labelling_en

"Fleet DNA Project Data.” 2017. National Renewable Energy Laboratory. https://www.nrel.gov/transportation/fleettest-fleet-dna.html

Florida Department of Transportation. 2016. Florida Motorcycle Strategic Safety Plan. https://fdotwww.blob.core.windows.net/sitefinity/docs/default-source/safety/safety/2aprograms/motorcycle/floridamotorcyclesafetyplann2016.pdf?sfvrsn=ac7b25a2 0

Fortenbery, T. Randall. 2005. Biodiesel Feasibility Study: An Evaluation of Biodiesel Feasibility in Wisconsin. University of Wisconsin-Madison. Staff Paper Series No. 481.37 p. http://www.aae.wisc.edu/pubs/sps/pdf/stpap481.pdf

Gaines, Linda, and Patricia Weikersheimer. 2016. Idling Reduction for Long-Haul Trucks: An Economic Comparison of On-Board and Wayside Technologies. Argonne, IL: Argonne National Laboratory Energy Systems Division. Report No. ANL/ESD-16/16. https://anl.app.box.com/s/ordxowhhcqrp7fe3yd3oy2fapwt3fpiw

Global Fuel Economy Initiative. Fuel Economy State of the World 2016 - Time for Global Action. Eds. Alex Körner Sheila Watson. Produced by FIA Foundation. www.globalfueleconomy.org/media/203446/gfei-state-of-the-world-report-2016.pdf

Google. "The Transport Tracker Solution." https://developers.google.com/maps/solutions/transport-tracker/

Google. "Transit." https://github.com/google/transit

Hausman, Jerry A. 1979. Individual discount rates and the purchase and utilization of energyusing durables. Bell journal of Economics 10.1 (1979): 33-54.

Howell, David, Brian Cunningham, Tien Duong, and Peter Faguy. 2016. "Overview of the DOE VTO Advanced Battery R\&D Program.” Washington, DC: U.S. Department of Energy: Office of Energy Efficiency and Renewable Energy.

https://energy.gov/sites/prod/files/2016/06/f32/es000 howell 2016_o web.pdf

International Energy Agency. 2017. International Comparison of Light-Duty Vehicle Fuel Economy 2005-2015 - Ten Years of Fuel Economy Benchmarking. International Energy Agency - Working Paper 15.

Jääskeläinen, Hannu. 2009 "Biodiesel Standards \& Properties.” Ecopoint, Inc., dieselnet.com, revision 2009.01f. https://www.dieselnet.com/tech/fuel biodiesel std.php 
Jamaica Information Service. 2011. "Jamaica Looks at Castor Oil as a Biofuel." Jamaica Information Service, February 14, 2011. https://jis.gov.jm/jamaica-looks-at-castor-oil-as-abiofuel-2/

Jamaica Ministry of Finance and the Public Service. 2017. Revenue Measures for Fiscal Year 2017/18. Jamaica: Ministry of Finance and the Public Service, Ministry Paper No. 17/17. http://go-jamaica.com/revenuemeasures/

Jamaica Observer. 2015. "Digicel Jamaica's Smartphone Users Surpass 1 Million.” January 10, 2015. http://www.jamaicaobserver.com/business/Digicel-Jamaica-s-smartphone-users-surpass-1million 18201974

Jamaica Observer. 2015. "Paid parking in Kingston as of June 1.” April 15, 2015. www.jamaicaobserver.com/news/Paid-parking-in-Kingston-as-of-June-1 95679

Litman, Todd. 2016a. Parking Management: Strategies, Evaluation and Planning. Victoria Transport Policy Institute. 32 p. www.vtpi.org/park_man.pdf

Litman, Todd. 2016b. Parking Requirement Impacts on Housing Affordability. Victoria Transport Policy Institute. 39 p. http://vtpi.org/park-hou.pdf

Litman, Todd. 2018. Generated Traffic and Induced Travel: Implications for Transport Planning. Victoria Transport Policy Institute. 39 p. www.vtpi.org/gentraf.pdf

Logistics Manager. 2007. "Double Deckers for Royal Mail.” Logistics Manager Magazine. September 19, 2007. https://www.logisticsmanager.com/7652-double-deckers-for-royal-mail/

Lutsey, Nicholas, Christie-Joy Brodrick, Daniel Sperling, and Carollyn Oglesby. 2004. "Heavyduty truck idling characteristics: results from a nationwide truck survey." Transportation Research Record: Journal of the Transportation Research Board 1880 (2004): 29-38.

Mandolesi de Araújo, Carlos Daniel, Claudia Cristina de Andrade, Erika de Souza e Silva, and Francisco Antonio Dupas. 2013. "Biodiesel Production from Used Cooking Oil: A Review." Renewable and Sustainable Energy Reviews 27: 445-452. https://www.sciencedirect.com/science/article/pii/S1364032113003912

Mapatón. 2016. "Sé parte del primer maratón de mapeo colectivo de recorridos de microbús, autobús y vagoneta en la Ciudad de México.” (in Spanish). http://mapatoncd.mx/

Mass Transit Magazine. 2016. "Best Practices: First-Last Mile Strategies.” August 15, 2016. https://www.masstransitmag.com/article/12225894/best-practices-first-mile-last-milecollaboration

Mims, Natalie, and Heidi Hauenstein. 2008. Feebates: A Legislative Option to Encourage Continuous Improvements to Automobile Efficiency. Rocky Mountain Institute. https://rmi.org/wp-content/uploads/2017/05/RMI_Document_Repository_PublicReprts Feebate final.pdf 
Ministry of Science, Energy and Transportation. "Petroleum Consumption by Product." Jamaica Ministry of Science, Energy and Transportation. http://mset.gov.jm/petroleum-consumptionproduct

Mock, Peter. 2013. "Fuel Economy Labels: Focus on non-EU Countries." Presented at IEA Paris, April 30, 2013. International Council on Clean Transportation. www.iea.org/media/workshops/2013/gfeilabelling/02.ICCT.130430ICCTCO2labelingoutsideEU . pdf

N.C. Department of Environmental Quality. "North Carolina Recycling Markets Directory." Recycling Business Assistance Center (RBAC) in the Division of Environmental Assistance and Customer Service, N.C. Department of Environmental Quality. Accessed 9/12/18 at http://www.p2pays.org/dmrm/start.aspx?id=51

Narassimhan, Easwaran, and Caley Johnson. 2018. "The Role of Demand-Side Incentives and Charging Infrastructure on Plug-In Electric Vehicle Adoption: Analysis of US States." Environmental Research Letters. 13: 074032. http://iopscience.iop.org/article/10.1088/17489326/aad0f8/meta

National Association of City Transportation Officials. Urban Bikeway Design Guide. New York, NY: National Association of City Transportation Officials. https://nacto.org/publication/urbanbikeway-design-guide/bikeway-signing-marking/shared-lane-markings/

National Center for Statistics and Analysis. 2018, March-Revised. Pedestrians: 2016 Data. Traffic Safety Facts. Report No. DOT HS 812 493. Washington, DC: National Highway Traffic Safety Administration. https://crashstats.nhtsa.dot.gov/Api/Public/ViewPublication/812493

National Environment and Planning Agency. 2007. Development and Investment Manual. Kingston, Jamaica: Office of the Cabinet, Government of Jamaica. http://nepa.gov.jm/Development-Invest-Man/

National Renewable Energy Laboratory. 2015. "DRIVE: Drive-Cycle Rapid Investigation, Visualization, and Evaluation Analysis Tool.” Golden, CO: National Renewable Energy Laboratory. https://www.nrel.gov/transportation/drive.html

New Zealand Ministry of Transport. 2018. "Transport Volume: Vehicle Travel.” accessed March 19, 2018. http://www.transport.govt.nz/ourwork/tmif/transport-volume/tv002/

N.J. Department of Environmental Protection. 2015. "No Idling Zone Signs." State of New Jersey Department of Environmental Protection Bureau of Mobile Resources. https://stopthesoot.org/sts-no-idle-sign.htm

Paraiba, Orlando, Marta Catalão Oliveira, Stavroula Tournaki, Theocharis Tsoutsos, Pablo Quero García, José María Llaves Ruiz, Filippo Giglio, Carmine Brescia, Valeria Magnolfi, Carla Uggè, Maurizio Cocchi, Dalila Antunes, João Braga, Susana Camacho, Monica Filice, Louise Krogh Johnson, Kyriakopoulos Yorgos, and Harris Adrianos. 2015. RecOil: Used Cooking Oil to Biodiesel Guide. European Commission. 
https://www.researchgate.net/publication/281347879 RecOil Used Cooking Oil to Biodiesel Guide

Saunderson, Michael. 2017. Road Congestion Impact on Public Transport-Jamaican Perspective. Government of Jamaica, National Works Agency.

Scheewe, Winfred. Coconut Farm Diversification - Ideas and Considerations. 2003. Group of Advocates for Sustainable Agriculture, Inc. Tandag, Surigao del Sur, Philippines. https://www.scribd.com/document/329707238/Coconut-Farm-Diversification-Gasa-EnglCorrected-2016-09-15

Shoup, Donald C. 2006. "Cruising for Parking." Transport Policy. 13: 6, 479-486. https://www.sciencedirect.com/science/article/pii/S0967070X06000448

Statistical Institute of Jamaica. 2011. "Census of Jamaican Population." Government of Jamaica, Ministry of Economic Growth and Job Creation, Statistical Institute of Jamaica (STATIN). http://statinja.gov.jm/Census/PopCensus/Popcensus2011Index.aspx

Sutherland, Ronald J. 1991. "Market Barriers to Energy Efficiency Investments." The Energy Journal. 12: 3 15-34. https://www.jstor.org/stable/41322426?seq=1\#page_scan tab contents

The League of American Bicyclists. 2019. "Model Safe Passing Law." https://bikeleague.org/content/model-safe-passing-law-0

Toll Authority of Jamaica. 2018. "About the Toll Authority of Jamaica." Ministry of Transport and Mining, Toll Authority of Jamaica. https://tollauthority.gov.jm/about/\#services

Transportation Authority. 2013. "Public Passenger Vehicles." Kingston, Jamaica: Government of Jamaica, Transportation Authority. http://www.ta.org.jm/typesofroadlicences

U.S. Department of Energy. Washington, DC: U.S. Department of Energy. Last updated February 27, 2019. www.fueleconomy.gov

U.S. Department of Transportation Federal Highway Administration. 2018. "Annual Vehicle Distance Traveled in Miles and Related Data - 2016 by Highway Category and Vehicle Type." Last updated October 11, 2018.

https://www.fhwa.dot.gov/policyinformation/statistics/2016/vm1.cfm

U.S. Department of Transportation Federal Highway Administration. 2010. Public Policies for Pedestrian and Bicyclist Safety and Mobility: An Implementation Project of the Pedestrian and Bicyclist Safety and Mobility International Scan (Review). Washington, DC: U.S. Department of Transportation Federal Highway Administration. 68 p. www.pedbikeinfo.org/cms/downloads/PBSPolicyReview.pdf

U.S. Department of Transportation Federal Highway Administration. 2016. Decision Support Guide for the Installation of Shoulder and Center Line Rumble Strips on Non-Freeways. Washington, DC: U.S. Department of Transportation Federal Highway Administration. Report No. FHWA-SA-16-115. 61 p. 
https://safety.fhwa.dot.gov/roadway dept/pavement/rumble strips/fhwasa16115/fhwasa16115.p df

U.S. Department of Transportation Federal Highway Administration. "Highway Statistics 2016, Annual Vehicle Distance Traveled in Miles and Related Data -2016 by Highway Category and Vehicle Type." Washington, DC: U.S. Department of Transportation Federal Highway Administration. Revised May 2018. www.fhwa.dot.gov/policyinformation/statistics/2016/vm1.cfm

U.S. Environmental Protection Agency. "SmartWay Verified List of Idling Reduction Technologies (IRTs) for Trucks and School Buses." Washington, DC: U.S. Environmental Protection Agency. Last updated October 3, 2018. https://www.epa.gov/verified-dieseltech/smartway-verified-list-idling-reduction-technologies-irts-trucks-and-school

U.S. Environmental Protection Agency. 2006. Compilation of State, County, and Local AntiIdling Regulations. Washington, DC: U.S. Environmental Protection Agency Office of Transportation and Air Quality. Report No. EPA420-B-06-004. www.epa.gov/sites/production/files/documents/CompilationofStateIdlingRegulations.pdf

U.S. Foreign Agricultural Service. 2017. Philippines Biofuels Annual - Philippine Biofuels Situation and Outlook. U.S. Foreign Agricultural Service, Global Agricultural Information Network. Prepared by Perfecto Corpuz. GAIN report No. RP1713. https://gain.fas.usda.gov/Recent\%20GAIN\%20Publications/Biofuels\%20Annual_Manila_Philip pines 10-18-2017.pdf

United Nations, Department of Economic and Social Affairs, Population Division. 2017. World Population Prospects: The 2017 Revision, Key Findings and Advance Tables. Working Paper No. ESA/P/WP/248. https://esa.un.org/unpd/wpp/Publications/Files/WPP2017_KeyFindings.pdf

United Nations. 2015. Intended Nationally Determined Contribution of Jamaica. United Nations Framework Convention on Climate Change. NDC Registry (Interim). https://www4.unfccc.int/sites/ndestaging/PublishedDocuments/Jamaica\%20First/Jamaica\%27s\% 20INDC_2015-11-25.pdf

United Nations. 2015. Intended Nationally Determined Contribution of Jamaica. United Nations Framework Convention on Climate Change. NDC Registry (Interim). www4.unfecc.int/ndcregistry/PublishedDocuments/Jamaica\%20First/Jamaica's\%20INDC_201511-25.pdf

United Nations. 2017. World Population Prospects 2017. https://population.un.org/wpp/

Wiltsee, G. 1998. Urban Waste Grease Resource Assessment. National Renewable Energy Laboratory. Report NREL/SR-570-26141. http://www.nrel.gov/docs/fy99osti/26141.pdf

Wood, Joanne M., Richard A. Tyrrell, Ralph Marszalek, Philippe Lacherez, Trent Carberry, and Byoung Sun Chu. 2012. "Using Reflective Clothing to Enhance the Conspicuity of Bicyclists at Night.” Accident Analysis \& Prevention. 45: 726-30, https://doi.org/10.1016/j.aap.2011.09.038. 
World Bank. 2013. Motor Vehicles per 1,000 People. Indicator ID: IS.VEH.NVEH.P3. https://datacatalog.worldbank.org/motor-vehicles-1000-people

World Health Organization. 2013. Pedestrian Safety - A Road Safety Manual for DecisionMakers and Practitioners. Geneva, Switzerland: World Health Organization. 132 p. http://apps.who.int/iris/bitstream/10665/79753/1/9789241505352_eng.pdf?ua=1 


\section{Appendix A. 2050 Wedge Analysis}

Jamaica is already beginning to consider steps beyond its 2030 goal. To facilitate this planning, we ran a scenario of how Jamaica's ground transportation sector could achieve an $80 \%$ reduction in GHG emissions by 2050.

The 2050 base case was derived the same way as the 2030 case. As shown in Figure 3, personal VKT per capita is estimated to be $4,612 \mathrm{~km}$ by 2050 . The freight/personal VKT ratio in the base case is assumed to stay the same, so total VKT per capita is $5,363 \mathrm{~km}$. After taking the UN 2050 population projections into account (UN 2017), we see that the VKT annual growth rate of $1.2 \%$ (the same as applied to the 2016-2030 BAU case) applies to the 2016-2050 time period as well. This same growth rate was used to set the BAU petroleum use and GHG emissions projections, as represented by the top line in Figure A1.

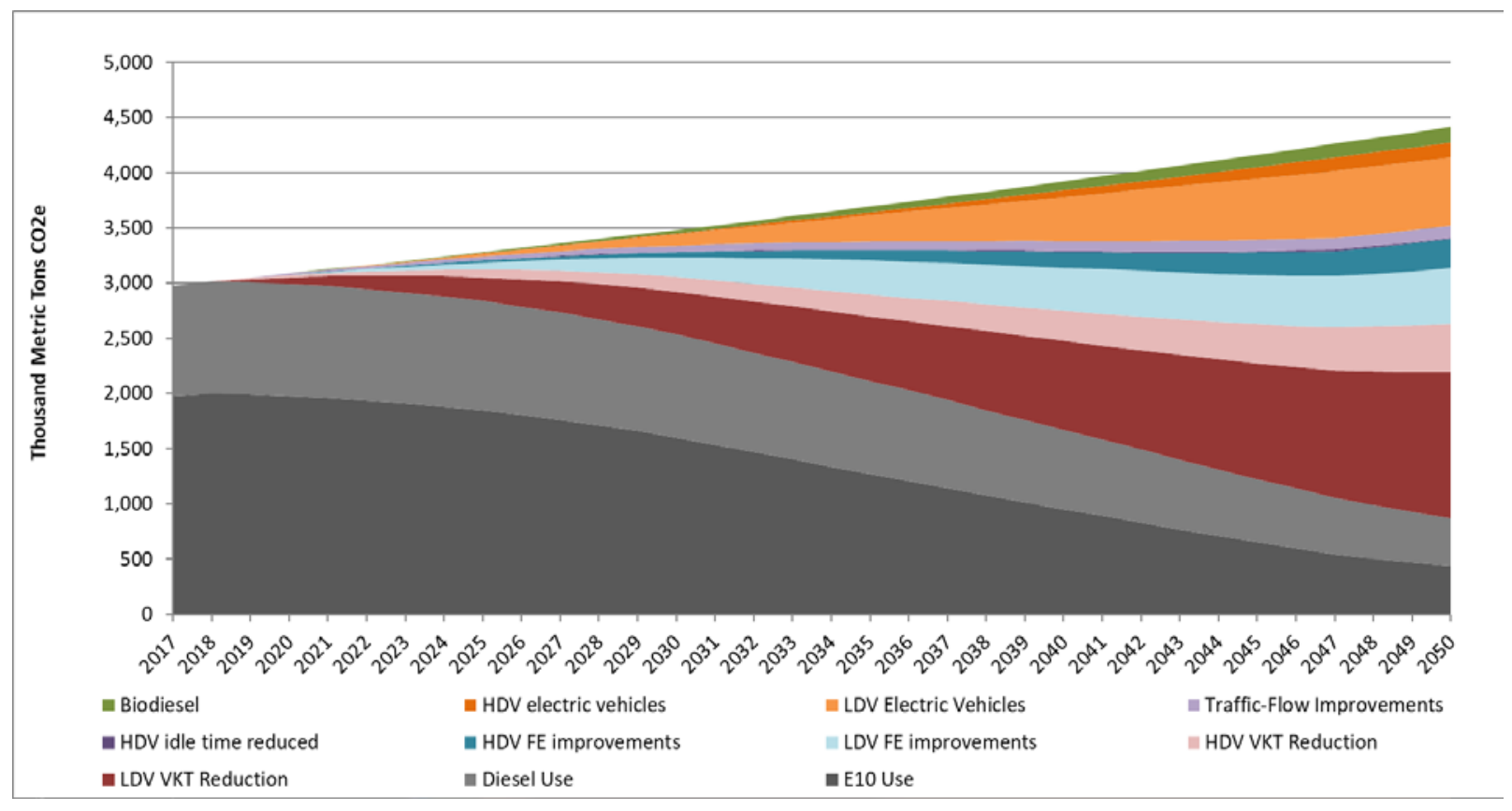

Figure A1. Reduction wedges to reduce Jamaica's transport emissions $80 \%$ below BAU by 2050

Subgoals were modeled to explore options for achieving an $80 \%$ reduction in emissions by 2050 . The subgoals reflected in Table A1 are much more aggressive than the 2030 subgoals (Figure 3), reflecting the additional time allotted to achieve them and the greater overarching goal. Three new subgoals - HDV VKT reduction, HDV fuel economy improvements, and electric HDVsare also introduced. The 2050 subgoals are described below. 
Table A1. Subgoals, Their Predicted GHG Reduction, and Percent Contribution to Overall 2050 Goals

\begin{tabular}{lll}
\hline Subgoal (from 2050 BAU) & $\begin{array}{l}\text { TMT } \mathbf{C O}_{2} \mathbf{e} \\
\text { reduced }\end{array}$ & $\begin{array}{l}\text { Percent of } \\
\text { Overall } \\
\text { Goal }\end{array}$ \\
\hline $\begin{array}{l}\text { 44\% Reduction in VKT of LDVs through walking, biking, transit, } \\
\text { ridesharing, and telecommuting }\end{array}$ & $1,288.7$ & 36.5 \\
$\begin{array}{l}50 \% \text { of new LDV purchases to be electric } \\
75 \% \text { Improvement in fuel economy for new LDVs }\end{array}$ & 621.7 & 17.6 \\
$\begin{array}{l}\text { 30\% Reduction in VKT of HDVs through route optimization and } \\
\text { vehicle consolidation }\end{array}$ & 506.1 & 14.3 \\
$50 \%$ Improvement in fuel economy for new HDVs & 446.8 & 12.6 \\
$\begin{array}{l}\text { All diesel contains 20\% biodiesel } \\
\text { 25\% of new HDV purchases to be electric }\end{array}$ & 263.0 & 7.4 \\
$\begin{array}{l}\text { Traffic-flow is smoothed so that 20\% of road kilometers are } \\
\text { converted from city drive cycle to highway drive cycle }\end{array}$ & 142.7 & 4.0 \\
HDV idle time reduced 1 hour per vehicle per day & 137.6 & 3.9 \\
\hline
\end{tabular}

1. Forty-four percent reduction in VKT of LDVs through walking, biking, transit, ridesharing, and telecommuting. This subgoal is very aggressive but becomes more achievable after the United Nations-projected population decrease of $6 \%$ is taken into account (United Nations 2017). To achieve this GHG reduction, the government could use price signals through increased fees associated with vehicle registration, parking, and fuel or carbon taxes. This subgoal is expected to provide $36.5 \%$ of the emissions reductions needed to achieve the overall 2050 goal - more than the next two subgoals combined.

2. Fifty percent of new LDV purchases to be electric by 2050 . This is paired with an assumption that $60 \%$ of Jamaica's electricity comes from renewable sources (replacing all fuel oil) and 40\% comes from natural gas. Fifty percent EVs by 2050 is less than the 2018 EV market forecast done by Bloomberg New Energy Finance (BNEF) where 55\% of new LDV sales are EVs by 2040 (BNEF 2018). BNEF derived this forecast by comparing the production costs of EVs and conventional vehicles over time. It estimates EV production costs to drop below their conventional counterparts by 2030 , resulting in a greater number of EV purchases.

3. Seventy-five percent improvement in fuel economy for new LDVs. This would bring the average fuel economy of new LDVs from $9.0 \mathrm{~L} / 100 \mathrm{~km}$ (per Table 2) to $2.25 \mathrm{~L} / 100 \mathrm{~km}$ in 2050. This could be achieved if Jamaica met the Global Fuel Economy Initiative goal of $4.2 \mathrm{~L} / 100 \mathrm{~km}$ by 2030 and then relaxed its pace of progress from $5 \%$ per year to $3 \%$ per year for the next 20 years. $2.25 \mathrm{~L} / 100 \mathrm{~km}$ is close to 100 miles per gallon-the fuel economy target for the $2010 \mathrm{X}$-Prize competition that multiple teams achieved (Ahrens 2010). 
4. Thirty percent reduction in the VKT of HDVs (while assuming that a proportional share of these will be EVs and that $60 \%$ of Jamaica's electricity is from renewable sources and $40 \%$ from natural gas). This can be pursued through route optimization software (such as the products listed and rated on Capterra's website [Capterra 2018]), truck consolidation (such as that done by the Royal Mail when it adopted double-deck trailers [Logistics Manager 2007]), and bus consolidation (which would entail more articulated buses in the JUTC fleet). It should be noted that the VKT reduction in LDVs would likely increase bus ridership, which would increase the difficulty of HDV VKT reduction.

5. Fifty percent improvement in HDV fuel economy. This is within the range of four major studies assessing the potential improvements in the United States and European HDV markets (Global Fuel Economy Initiative 2016). Furthermore, efficient vehicles should become more available because the United States, Canada, Japan, and China (which collectively cover nearly half of the global market) have now adopted national efficiency regulations for HDVs that are to achieve between $10 \%$ and $14 \%$ fuel reduction by 2030 .

6. All road transportation diesel contains $20 \%$ biodiesel (B20). This blend level is accepted by most diesel engine manufacturers (that sell to the U.S. market) without voiding the warranty (Biodiesel 2012). Furthermore, Jamaica's warm climate is particularly conducive to higher biodiesel blends because it preempts cold-start issues. Based on estimates in Appendix C, $60 \%$ of the biodiesel needed for B20 (in 2018) could likely be sourced from domestic waste oil and grease. The remaining 40\% (26 million L) could likely be produced from domestic jatropha, castor, or coconut oil. The Petroleum Corporation of Jamaica has already performed a pilot project testing the viability of growing castor and jatropha on mined-out bauxite quarries (Jamaica Information Service 2011). Alternatively, Jamaica has good growing conditions for coconuts. Production could be sustainably increased by growing coconuts over top of other crops already being grown (Scheewe 2003). The Coconut Industry Board could interface with the Philippine Coconut Authority for lessons and techniques on how it is overcoming hurdles to meet its nationwide B5 mandate (U.S. Foreign Agricultural Service 2017).

7. Twenty-five percent of new HDV sales are EVs by 2050. The global HDV EV market is less developed than its LDV counterpart, but it is positioned for robust growth. Transit buses are particularly well suited for electric drivetrains, and manufacturers are offering an increasing variety of electric buses (e-buses) every year. In 2017 there were 385,000 e-buses on the road and 13 major cities pledged to procure only zero-emissions buses (mostly electric) from 2025 onward (BNEF 2018). The momentum of the e-bus market is such that BNEF forecasts $15 \%$ to $35 \%$ of all municipal bus sales globally to be electric by 2030 (BNEF 2018). The EV market for other HDVs is further behind that of e-buses. However, the number of electric truck manufacturers is growing, their products stand to benefit from the progress made by e-bus manufacturers, and many other HDV fleet vehicles have drive cycles that are well suited to capitalize on the benefits that electric drivetrains offer (National Renewable Energy Laboratory 2017).

8. HDV idle time reduced by 1 hour per day. This is assumed to be a reasonable amount of idle time to cut since, as explained in Section $4,90 \%$ of the trucks on the U.S. mainland idle more than 48 minutes per day. The technologies and policies to reduce idle time are well established and effective in locations where they have been implemented. 
9. Traffic flow is smoothed so that $20 \%$ of road kilometers, weighted by traffic volume, are converted from a city drive cycle to a highway drive cycle. This ambitious subgoal will be greatly facilitated by the VMT-reduction efforts, as it should reduce congestion and therefore improve drive cycles. Jamaica's trend of developing thoroughfares and toll roads such as A1, T1, and Port Kingston Causeway should also greatly improve drive cycles. 


\section{Appendix B. Supplemental Wedge Model Details}

The wedge model accounts for GHG reductions in a specific order to minimize double counting and to track the impact that one subgoal has on others. Further clarity is gained by accounting for the type of petroleum fuel — diesel or gasoline - associated with each wedge. All wedge tracking assumes that LDVs use gasoline and HDVs use diesel.

The VKT reductions are taken first, because any progress in this wedge affects the amount of gasoline use available to be reduced by any of the other wedges. We assume that all VKT reduction projects will be aimed at LDVs that use gasoline. This does not account for the potential increase in bus use due to increased mass transit, so non-bus HDVs may need to reduce VKT to make up for any increase by buses.

The Electric Vehicle and Fuel Economy wedges are based on new LDV sales. Therefore, for purposes of calculation, we assume that the pool of vehicles has been reduced commensurately with VKT. Although this will not necessarily be the case, it does not distort fuel-use reduction figures, since both the number of vehicles and per-vehicle VKT are multiplied (over fuel economy) when fuel use is calculated. After taking this LDV reduction into account, we predict annual LDV sales by looking at the number of vehicles that would be replaced any given year. The Electric Vehicle wedge is first calculated off this value, and the Fuel Economy wedge is then derived from the remainder of new vehicles, after the EVs are subtracted from the annual vehicle sales.

The Electric Vehicle and Fuel Economy goals are set to apply only to LDVs, because gasoline use represents a greater share of Jamaica's petroleum use than diesel use does. We apply the fuel economy goal only to gasoline-powered LDVs, because there is greater potential for fuel economy improvements in this sector. This is largely because fleets tend to consider life cycle fuel costs and other operating costs when purchasing HDVs, making fuel economy a major factor in acquisitions. In contrast, individuals who purchase LDVs (or any other energyconsuming device) tend to prioritize upfront cost over lifetime fuel savings (Hausman 1979), so they do not maximize fuel economy.

Fuel (both gasoline and diesel) saved through traffic signal synchronization is applied after the Fuel Economy wedge, because the latter is based on the U.S. Environmental Protection Agencylabeled fuel economy and does not take traffic flow into account. The Traffic Flow Improvement wedge is independent from the IR wedge, since there is no quantifiable relationship between the two. Diesel saved from both wedges is subtracted from the amount of diesel used before B5 is applied to the remaining diesel use.

We assume that most projects will be phased in on a regular schedule. Some schedules, like that for EVs, do not begin immediately though, because we deem it a better use of financial resources to wait until prices drop. Furthermore, dealers must develop the capability to service EVs, after which point we expect adoption to grow fairly quickly. Some schedules, like that of biodiesel, occur in large steps, because we assume that production capacity must be developed in discrete phases that coincide with infrastructure development. The Fuel Economy wedge starts immediately and grows at a steady rate because fuel economy regulations took effect in 2012 , and we assume a steady rate of LDV scrappage over time. The Traffic Flow wedge manifests its petroleum-use reductions in a single jump, since it requires a central infrastructure project. The 
VKT and IR wedges gradually ramp up over time, since they require behavioral change and numerous small investments. 


\section{Appendix C. Estimates of Potential Biodiesel Produced from Used Cooking Oil and Waste Grease}

Used Cooking Oil. The population of Jamaica is 2,881,355 (United Nations 2017) and the average household size is 3.1 people (ArcGIS 2013), meaning that there are 929,469 households in Jamaica. We assume that each household uses 7 kilograms $(\mathrm{kg})$ of cooking oil because that is what a Brazilian household uses (Mandolesi de Araújo et al. 2013). Eighteen percent of that amount gets absorbed into the food (Mandolesi de Araújo et al. 2013), leaving 5.3 million kg or 4.9 million L of UCO available for biodiesel. Biodiesel has a $94 \%$ conversion rate (Mandolesi de Araújo et al. 2013), meaning that 4.6 million L can be produced each year, which is $30 \%$ of the 15.5 million $\mathrm{L}$ that would be required to make all road diesel B5 in 2018.

Waste Grease. Each U.S. citizen produces $10.4 \mathrm{~kg}$ of waste grease per year (Wiltsee 1998), so we assume that the same holds true for Jamaicans. A total of $0.96 \mathrm{~kg}$ of waste grease is used to produce 1 L of biodiesel (Fortenbery 2005), so 31 million L of biodiesel could be produced from waste grease in Jamaica. This is about twice the amount that would be needed to make all diesel B5 in 2018. 